\title{
Observations of nonlinear internal waves at a persistent coastal upwelling front
}

\author{
Ryan K. Walter ${ }^{1 *}$, Marek Stastna ${ }^{2}$, C. Brock Woodson ${ }^{3}$, and Stephen G. Monismith ${ }^{4}$ \\ *Corresponding author: rkwalter@ calpoly.edu \\ ${ }^{1}$ Physics Department, California Polytechnic State University, San Luis Obispo, CA, USA \\ ${ }^{2}$ Department of Applied Mathematics, University of Waterloo, Waterloo, ON, Canada \\ ${ }^{3}$ COBIA Lab, College of Engineering, University of Georgia, Athens, GA, USA \\ ${ }^{4}$ Environmental Fluid Mechanics Laboratory, Stanford University, Stanford, CA, USA
}




\begin{abstract}
We collected high-resolution observations of nonlinear internal waves (NLIWs) at a persistent upwelling front in the shallow coastal environment ( 20 m) of northern Monterey Bay, CA. The coastal upwelling front forms between recently upwelled waters and warmer stratified waters that are trapped in the bay (upwelling shadow). The front propagates up and down the coast in the along-shore direction as a buoyant plume front due to modulation by strong diurnal wind forcing. The evolution of the coastal upwelling front, and the subsequent modulation of background environmental conditions, is examined using both individual events and composite day averages. We demonstrate that regional-scale upwelling and local diurnal wind forcing are key components controlling local stratification and the formation of internal wave guides that allow for high-frequency internal wave activity. Finally, we discuss the ability of theoretical models to describe particularly large-amplitude internal waves that exist in the presence of a strong background shear and test a fully nonlinear model (i.e., the Dubreil-Jacotin-Long equation).
\end{abstract}

Keywords: Internal waves; coastal and nearshore processes; coastal upwelling; upwelling front; diurnal wind forcing 


\section{Introduction}

Nonlinear internal waves (NLIWs) are a widespread feature of the coastal ocean (e.g., Klymak and Moum, 2003; Moum et al., 2003; Hosegood and van Haren, 2004; Scotti and Pineda, 2004; Nash and Moum, 2005; Bourgault et al., 2007; Woodson et al., 2011; Alford et al., 2012; Jackson et al., 2012; van Haren et al., 2012; Walter et al., 2012, 2014a, 2014b; Cheriton et al., 2014a, 2014b; Suanda et al., 2014;), and often play a key role in cross-shelf exchange of nutrients, sediments, and contaminants (Sandstrom and Elliot, 1984; Leichter et al., 1996; Boehm et al., 2002; Hosegood and van Haren, 2004; Quaresma et al., 2007); dissolved oxygen variability (Booth et al., 2012; Walter et al., 2014a); larval transport (Pineda 1991, 1994, 1999); and turbulent dissipation and diapycnal mixing (Moum et al., 2003; Hosegood and van Haren, 2004; Venayagamoorthy and Fringer, 2007; Woodson et al., 2011; van Haren et al., 2012; Walter et al., 2012; Walter et al., 2014a). NLIWs in the stratified coastal ocean thus represent an important problem from a fundamental and practical standpoint with significant implications for many physical and biological processes.

NLIWs in the coastal environment are an established topic of study in theoretical, numerical, and experimental fluid mechanics (cf. Helfrich and Melville, 2006; Lamb, 2014). However, previous computational and theoretical efforts have necessarily concentrated on simplified and idealized setups (Lamb, 2014), while observational studies have mainly focused on deeper shelf waters (50+ m depths; e.g., Table 1 of Alford et al. 2012). There is a lack of high-resolution observations of internal waves in shallower waters ( 20 m; cf. Woodson et al., 2011; van Haren et al., 2012; Walter et al. 2012, 2014a, 2014b), an area of the ocean with rapidly changing dynamics and important ecological habitats such as kelp forests and coral reefs. Indeed, the lifecycle of shallow water NLIWs takes place in a highly dynamic environment, with 
spatiotemporal changes in background environmental conditions such as stratification, velocity shear, and tidal and wind forcing. In this study, we take advantage of high-resolution measurements to examine the role of rapidly changing background conditions on the internal wave environment at a shallow coastal upwelling site.

During the summer upwelling season ( April to September), a coastal upwelling front forms in northern Monterey Bay, CA. Regional upwelling favorable winds generate a strong upwelling jet at Point Año Nuevo that flows southward across the mouth of the bay (Rosenfeld et al., 1994). Waters within the bay are shielded from regional upwelling by the Santa Cruz Mountains. This results in a warm lens of water inside the bay, a region termed the "upwelling shadow" (e.g., Graham and Largier, 1997; Woodson et al., 2009). Thus, a sharp coastal upwelling front forms and persists between the warm upwelling shadow waters and cooler waters from the offshore upwelling jet (Figure 1a).

Woodson et al. (2009) examined the regional and local forcing mechanisms of the upwelling front using an array of moorings during the summer upwelling season and concluded that the front propagates poleward as a buoyant plume due to regional barotropic (due to regional wind forcing) and baroclinic (due to the temperature differences across the front) pressure gradient forces. The authors also found that on a local scale, a diurnal sea breeze modulates the daily propagation of the front up and down the coast in the along-shore direction (up to $5 \mathrm{~km}$ a day). During the late evening and early morning when the local diurnal winds are weak, the front propagates out of the bay (along-shore poleward) due to the background baroclinic and barotropic pressure gradients. However, as the diurnal winds strengthen in the afternoon, the front decelerates and reverses back into the bay so that it propagates downwind. The front 
propagates downwind until the sea breeze relaxes in the evening, at which point the along-shore flow returns to its background poleward state.

Suanda et al. (2011) used long-term measurements near the upwelling front to examine the oceanic response to the diurnal wind forcing. They created a canonical day picture of temperature and currents that was phase-locked to the local diurnal wind forcing and evaluated terms in the heat budget of a two-dimensional cross-shelf section of the inner shelf. They concluded that during the evening and early morning periods when the winds are weak, observed temperature increases were mainly due to the along-shelf advection of a temperature gradient within the upwelling shadow zone. Specifically, the along-shelf heat flux explained $77 \%$ of the observed warming. This process was arrested during periods of strong local wind forcing in which case the front reversed to propagate downwind, corroborating the results of Woodson et al. (2009), and the wind-driven cross-shelf heat flux became important. Surface heat fluxes were nearly an order of magnitude smaller than the advective heat fluxes and did not contribute significantly to observed temperature changes. The authors also evaluated water column stability using the gradient Richardson number at three vertical locations and found that the water column is stable to shear-driven mixing for most of the day except for near-surface measurements following periods of maximum wind; however, the authors were limited in their vertical resolution to sufficiently resolve water column stability.

Woodson et al. (2011) observed packets of high-frequency NLIWs propagating along-shore equatorward near the location of the coastal upwelling front in the late afternoon during a oneweek sampling period. The authors focused on the description of the leading wave in a single packet of waves during the one-week sampling period using moored measurements of temperature at four vertical locations (4, 6, 8, and $14 \mathrm{~m}$ depth; $3 \mathrm{~s}$ sampling periods) in shallow 
water $(15 \mathrm{~m})$. They showed that the single wave packet led to enhanced turbulent dissipation and active mixing of the stratified interior. The authors suggested that the enhanced mixing was due to shear instabilities based on the ratio of the wave amplitude to the upper layer depth, although estimates of the gradient Richardson number were not quantified using the field observations. Moreover, the authors did not show or discuss variability in the internal wave field over the course of the one-week sampling period, nor did they assess the influence of changing environmental conditions (e.g., background stratification, regional and local wind forcing) on internal wave variability. Additionally, the authors used long-term moorings and synthetic aperture radar (SAR) images to document the consistent presence of NLIW packets during the late evening (2000 - 2300 local time). However, the long-term moorings did not provide sufficient temporal or spatial resolution to identify internal wave packet characteristics (cf. Woodson et al., 2011).

The aforementioned studies documented the regional and local forcing mechanisms of the front (Woodson et al, 2009; Suanda et al., 2011), as well as the presence of NLIWs near the front (Woodson et al., 2011), but they were limited in their ability to sufficiently resolve vertical variations and high-frequency changes in the internal wave field and background environmental conditions. In this contribution, we present high-resolution measurements of NLIWs at the coastal upwelling front using a moored instrument array. We expand on the previous observations with a better spatiotemporally resolved data set and provide a more detailed look into the evolution of the front and the subsequent modulation of background environmental conditions (e.g., stratification, velocity shear, etc.).

Subsequently, we examine the influence of these rapidly changing conditions on the highfrequency internal wave field. Several studies have addressed the effect of seasonal and 
interannual variations in stratification on internal wave behavior and activity (cf. Zhao et al., 2012; Hall et al., 2014; DeCarlo et al., 2015 and the references therein). More recent studies have illustrated the effect of low-frequency wind-driven upwelling and relaxation cycles on mid-shelf stratification and nearshore internal wave and bore variability (Walter et al., 2014b; Cheriton et al., 2014b). Cheriton et al. (2014b) found that regional wind-driven upwelling caused the appearance of a near-bottom secondary pycnocline, and hence internal wave guide, on the outer shelf $(70$ and $90 \mathrm{~m})$ of southern Monterey Bay. They concluded that upwelling-driven stratification is a first-order control on the ability of internal waves to propagate through continental shelf waters at that particular location.

In this contribution, we demonstrate how both regional-scale upwelling and local diurnal wind forcing are key components controlling local stratification and the formation of internal wave guides that allow for high-frequency internal wave activity. In contrast to previous studies, we find that during strong regional upwelling the advection of deep waters into the shallow environment results in a decrease in the local stratification, disappearance of the internal wave guide, and minimal internal wave variability. We also show that the local diurnal wind forcing is important for the along-shelf advection of a temperature gradient within the upwelling shadow zone, forming a transient internal wave guide that allows for periods of high-frequency internal wave activity at the study site. Finally, we discuss and explore the ability of theoretical models to describe particularly large-amplitude NLIWs that exist in the presence of a strong background shear and test a fully nonlinear model (i.e., the Dubreil-Jacotin-Long equation).

\section{Experimental Setup and Methods}

Moored instrument arrays were deployed from 7 to 22 July 2011 in order to describe the along-shore evolution of the upwelling front, background environmental conditions, and internal 
wave activity. Two moorings were deployed on the $\sim 20 \mathrm{~m}$ isobath roughly $220 \mathrm{~m}$ apart in the along-shore direction offshore of Sandhill Bluff, CA located in northern Monterey Bay (Figures $1 \mathrm{~b}$ and $1 \mathrm{c})$. This is the location of previous observations of frequent front crossings and alongshore equatorward propagating internal waves (Woodson et al. 2009, 2011). The northernmost mooring (FDN) was equipped with a dense vertical arrangement of SeaBird Inc. (SBE) SBE39 and SBE56 temperature loggers $(\mathrm{n}=17)$, with increased resolution $(0.5 \mathrm{~m}$ vertical spacing $)$ near the pycnocline region (Figure 1c). In order to capture the along-shore propagation of the front and internal waves, the southernmost mooring (FDS) was also equipped with thermistors, but with a lower vertical resolution $(\mathrm{n}=5$; Figure $1 \mathrm{c})$. Both moorings had SBE37 conductivitytemperature-depth (CTD) loggers bracketing the water column [1 and 18 meters above the bottom (mab)], as well as Teledyne-RDI $1200 \mathrm{kHz}$ Workhorse acoustic Doppler current profilers (ADCP). FDN's ADCP sampled in fast-ping mode 12 (8 subpings collected and averaged during each $1 \mathrm{~s}$ ensemble for an effective data recording rate of $1 \mathrm{~Hz}$; cf. Nidzieko et al., 2006) with 0.5 $\mathrm{m}$ vertical bin spacing, while FDS's ADCP sampled at $5 \mathrm{~s}$ with $0.5 \mathrm{~m}$ bins.

During the summer upwelling season, salinity variations on the shelf in Monterey Bay are sufficiently small so that density is largely controlled by temperature (e.g., Woodson et al. 2009, 2011; Walter et al. 2012, 2014a, 2014b; Zhao et al., 2012; etc.). Hence, we calculated density at all thermistor locations using the local measured temperature and the average of the top and bottom salinity measurements derived from the CTDs for each time interval; the average maximum error due to this approximation during each time interval is $0.016 \mathrm{~kg} / \mathrm{m}^{3}$. Local winds were obtained at five-minute intervals from Long Marine Laboratory (LML, Figure 1b), and regional offshore winds were collected at ten-minute intervals from the National Data Buoy Data Center (NDBC) buoy 46042 (36.785 N, 122.469 W, Figure 1a). Wind stresses were calculated 
using the method of Large and Pond (1981). All times referenced in the text and figures are in Pacific Daylight Time (PDT), unless otherwise noted.

\section{Figure 1 Location}

Spectral and coherence calculations were carried out using the fast Fourier transform (FFT) and standard methods (e.g., Walter et al., 2011). Hamming windows with 50\% overlap were applied between adjoining segments, where the window length was selected by taking into account the frequency resolution, the length of the original record, and the number of degrees of freedom (DOF) for confidence intervals. Spectra confidence intervals were calculated using the equivalent number of DOF (EDOF) and a chi-square variable analysis. For the coherence analysis, confidence limits were calculated using the EDOF (Emery and Thomson, 2001).

In order to examine the time-varying frequency content (power) of non-stationary processes, such as those associated with internal waves (Davis et al., 2008; Wong et al., 2012), several time series were decomposed into frequency-time space using continuous wavelet transforms following the methods outlined in Torrence and Compo (1998). The Morlet wavelet was employed as the mother wavelet function, where the nondimensional frequency parameter ( $\omega_{0}$ as in Torrence and Compo, 1998) is set to be equal to six in order to satisfy the necessary conditions that the wavelet function has zero mean, finite variance, and be localized in time and space (see Farge, 1992). The wavelet power spectrum is defined using the magnitude of the wavelet transform squared, $W=\left|W_{n}(s)\right|^{2}$, where $n$ is a localized time index and the wavelet scale $(s)$ is nearly identical to the Fourier period. In order to study the wavelet power in a particular band of scales (periods) over time, the scale-averaged wavelet power is calculated between scales (periods) $s_{1}$ to $s_{2}$ as follows:

$$
\langle W(t)\rangle=\frac{\delta j \delta t}{C_{\delta}} \sum_{j=j_{1}}^{j_{2}} \frac{\left|W_{n}\left(s_{j}\right)\right|^{2}}{s_{j}},
$$


where $\delta j$ is the scale resolution, $\delta t$ is the sampling time interval, and $C_{\delta}=0.776$ is a reconstruction constant. Wavelet power significance (confidence levels) is determined by comparing it to a background model spectrum of red-noise (i.e., univariate lag-1 autoregressive; cf. Torrence and Compo, 1998), an approach that has been successfully employed in previous studies to identify nonlinear internal waves (e.g., Wong et al., 2012). We refer the reader to Torrence and Compo (1998) for further details.

\section{Results and Discussion}

\subsection{General Observations}

Throughout the study period, regional offshore winds were largely upwelling favorable, though they varied in magnitude and exhibited a typical upwelling/relaxation cycle (Figure 2a). The local wind forcing was particularly strong and showed a distinct diurnal signal (Figures 2a and 3c). The temperature structure at the mooring site is marked by episodic frontal crossings delineated by sharp transitions from cool $\left(\sim 10^{\circ} \mathrm{C}\right)$ recently upwelled waters to warm $(\sim 12-15$ ${ }^{\circ} \mathrm{C}$ ) upwelling shadow waters (Figure $2 \mathrm{~b}$ ). Also evident during frontal crossings is the presence of higher-frequency temperature fluctuations due to internal wave forcing. The velocity field is dominated by a background along-shore poleward flow that is intensified during frontal crossings (Figure 2c). The background poleward current is consistent with barotropic and baroclinic pressure gradient-driven flows in the area (e.g., Drake et al., 2005; Woodson et al., 2009; Suanda et al., 2011). The middle portion of the record is characterized by extended regional upwelling favorable winds, as well as intensified local winds, so that the upwelling front is forced back into the bay (i.e., equatorward of the moorings) by the strong upwelling plume (cf. Figure 1a). During this period, the upwelling jet destratifies the water column at the mooring site (i.e., well-mixed waters near $10^{\circ} \mathrm{C}$ lasting several days, Figure $2 \mathrm{~b}$ ) and leads to a strong reversal 
of the background along-shore poleward flow (Figure 2c). This period with minimal stratification also precludes internal wave activity since there is no wave guide that allows for the propagation of internal waves (see also Section 3.2).

\section{Figure 2 Location}

During periods of weaker regional wind forcing, the upwelling front propagates poleward as a buoyant plume front and warm upwelling shadow waters are transported poleward with the preexisting background current. Analysis of temperature spectra as a function of depth reveals a dominant, surface-intensified signal in the diurnal frequency band (Figure 3a). The along-shore velocity field also reveals a surface-enhanced signal at the diurnal frequency, as well as a much weaker signal in the semidiurnal band that is constant with depth (Figure 3b). A coherence analysis between the temperature/along-shore velocity signals as a function of depth and the local winds reveals a statistically significant coherence at the diurnal frequency for both signals (not shown). These results are consistent with previous observations (Suanda et al., 2009; Woodson et al., 2011) that suggest the local diurnal winds are responsible for the daily modulation of the upwelling front up and down the coast. Moreover, the local winds are responsible for the surface-intensified diurnal variability in the along-shore velocity signal. In particular, the background poleward flow is arrested during the early afternoon by the local winds that accelerate an equatorward flow. When the local winds relax in the evening, alongshore currents return to their background poleward state. Since tidal effects at this particular location are minimal, the diurnal variability in the local temperature and velocity field is most likely wind-driven; this finding is corroborated by several other studies (see Rosenfeld et al. 2009; Wang et al. 2009; Suanda et al. 2011; Walter, 2014).

\section{Figure 3 Location}


In addition to decelerating and reversing the poleward propagating front, the local diurnal winds also lead to the development of surface-intensified velocity shear, particularly in the along-shore currents (Figure 4). Whereas this shear layer is typically confined to the upper portions of the water column, the shear-layer penetrates throughout the water column during the period of strong regional upwelling when the stratification is weak due to advection of wellmixed upwelling plume waters (cf. Rosenfeld et al., 2009) (Figure 4). The destabilizing effect of the local wind-driven shear is counteracted during periods of strong frontal activity, which are marked by enhanced water-column stratification due to the along-shore advection of warm, upwelling shadow waters (Figure 4d; cf. Suanda et al., 2011). The stability of the water column is characterized using the gradient Richardson number, $R i=N^{2} / S^{2}$, where $N^{2}=-\frac{g}{\rho_{o}} \frac{\partial \bar{\rho}}{\partial z}$ is the buoyancy frequency squared and $S^{2}=\left(\frac{\partial U}{\partial z}\right)^{2}+\left(\frac{\partial V}{\partial z}\right)^{2}$ is the total vertical shear in the horizontal direction. During frontal crossings, the majority of the water column is stable to shear instabilities $(R i>0.25)$, whereas near-surface and near-bottom regions often exhibit subcritical Richardson numbers $(R i<0.25)$. This is due to a combination of decreased stratification and enhanced velocity shear, as discussed in the next section. The large-scale temperature structure and dynamics are set by the regional upwelling favorable wind-forcing and the development of a coastal upwelling front. On a more local scale, the diurnal winds modulate the upwelling front up and down the coast. These processes combine to create a unique and dynamic environment with rapidly changing background environmental conditions (e.g., stratification, shear, stability, etc.).

\section{Figure 4 Location}

\subsection{Frontal Dynamics and NLIW Activity}

In this section we examine the evolution of the buoyant plume front and subsequent internal wave activity. We first consider the dynamics of the 17 July 2011 frontal crossing, 
which is highlighted by the some of the largest temperature gradients in the record (Figure 5). Prior to the arrival of the front, the water column is well mixed $\left(\sim 10^{\circ} \mathrm{C}\right)$, a trait that is indicative of recently upwelled waters (Figure 5b). The well-mixed waters poleward of the front do not provide a propagation pathway for internal waves, whereas the stratification in the upwelling shadow waters allow for internal wave propagation (i.e., wave guide). In the early morning, while the local along-shore winds are still weak, a sharp jump in temperature $\left(\Delta T \sim 3-4^{\circ} \mathrm{C}\right)$ occurs throughout the water column as the front propagates poleward on the preexisting background current (e.g., Woodson et al., 2009). Coincident with the frontal crossing is a sharp increase in the kinetic energy due to the change in the along-shore velocities $(\Delta v \sim 0.20-0.25$ $\mathrm{m} / \mathrm{s}$ ), as well as compensating offshore velocities near the bottom of the water column consistent with the large-scale structure described by Woodson et al. (2009). The increase in velocity shear (both the along- and cross-shore components) contributes to subcritical Richardson numbers $(R i<0.25)$ near the bottom and a region potentially unstable to shear instabilities. We note, however, that portions of the bottom of the water column are subcritical $(R i<0.25)$ prior to the arrival of the front due to the lack of stratification.

\section{Figure 5 Location}

Following the pulse of kinetic energy at the nose of the front and the subsequent development of a potentially unstable bottom region, the front detaches from the bed. Additionally, several hours following the development of an unstable bottom region, highfrequency fluctuations due to internal waves develop in the pynocline region and become more pronounced after the front detaches from the bed. Several hours later the diurnal winds start to increase and begin to arrest the poleward advection of the front and reverse the currents to flow equatorward (Woodson et al., 2009; Suanda et al., 2011), which indicate that the local diurnal 
winds are responsible for the flow reversal. The reversal of the buoyant plume front is also evident in the symmetry in the near-surface along-shore temperature gradient inferred from the Eulerian measurements in Figure 5b (e.g., near-surface temperature is approximately symmetric about 1500). The local diurnal wind stress also leads to the development of a near-surface region of enhanced velocity shear.

Following the modulation and reversal of the front by the local wind stress, the winds begin to relax. While the near-surface currents remain directed downwind (equatorward), the near-bottom currents return to flow poleward in the direction of the background state (cf. Woodson et al., 2009; Suanda et al., 2011). This results in a strong baroclinic flow with enhanced shear in the near-surface region that persists over the course of several hours. Regions with subcritical Richardson numbers $(R i<0.25)$ start to develop near the surface and penetrate into the thermocline region over this same time period. Following a period of time where a strong velocity shear persists, a rank-ordered packet of high-frequency NLIWs is observed at the mooring site. These very large-amplitude internal waves in shallow water (i.e., $\sim 10 \mathrm{~m}$ amplitude in $20 \mathrm{~m}$ of water) appear to exist in the presence of a strong background shear and a potentially dynamically unstable environment (cf. Stastna and Walter, 2014). Based on the arrival time of wave troughs between FDN and FDS, the waves are propagating along-shore equatorward (see next section), consistent with the directionality documented by Woodson et al. (2011). We note that NLIW signals are present at the mooring array throughout the aforementioned evolution of the front. It is likely that there are multiple generation mechanisms and sources of the NLIWs. Moreover, there are consistently large-amplitude internal waves (often rank-ordered packets) that appear following the poleward reversal of the near-bottom currents (black box with "NLIWs" label in Figure 5). These internal waves contain a strong along-shore velocity signature (i.e., 
high-pass filtered velocity field) and develop in the presence of strong background shear. These along-shore equatorward propagating waves appear to be a robust feature of the front, as documented over multiple-year records by Woodson et al. (2011).

\section{Figure 6 Location}

Examination of the dynamics during other frontal crossing events reveals many of the same basic features (e.g., 8 July 2011 shown in Figure 6). Notably, strong along-shore velocities in the warm buoyant waters mark the passage of the front with near-bottom velocities directed offshore at the nose of the front. Regions of subcritical Richardson number waters develop, the front begins to detach from the bed, and internal waves are seen in the thermocline region. Following this, the poleward advection of upwelling shadow waters is arrested and reversed by local diurnal wind forcing. This wind modulation results in the development of a strong nearsurface shear layer, and as the local winds start to relax, the bottom portion of the water column returns to flow poleward. This sheared, baroclinic flow results in a unique situation where largeamplitude internal waves with strong along-shore velocity signals develop in the presence of strong background shear and in regions where dynamical instabilities may exist (i.e., $R i<0.25$ ). This dynamic situation is schematized in Figure 7.

\section{Figure 7 Location}

In order to assess the effect of the various forcing regimes and temporally variable environmental conditions on high-frequency density fluctuations due to NLIWs at the front, we calculated the high-pass filtered ( $3 \mathrm{hr}$ half-amplitude period) density field using one minute density averages. Figure 8 highlights the depth-averaged density perturbation $\left(<\rho^{\prime}\right\rangle$, where the brackets denote a depth-average and the prime denotes a high-pass filtered quantity) over the entire record. Also plotted is the depth-averaged density stratification $\left(<N^{2}>\right)$. During the 
middle portion of the record when extended regional upwelling occurred (and well-mixed, $\sim 10^{\circ}$ $\mathrm{C}$ waters), density fluctuations and internal wave activity were minimal due to the lack of water column stratification. Conversely, the propagation of the buoyant plume front and advection of the stratified upwelling shadow waters during other time periods resulted in significant density perturbations.

\section{Figure 8 Location}

Wavelet analysis was employed to examine the time-varying frequency content of the density perturbations. The density perturbations consistently displayed high-frequency variability, with periods smaller than 1 hour, consistent with the large-amplitude NLIWs observed in Figures 5 and 6 . This variability coincides with the diurnal propagation of the buoyant plume front. We note that there is also significant variability at longer periods (i.e., 1 to 2 hours) due to the advection of upwelling shadow waters and the associated changes in the background stratification (cf. Suanda et al., 2011). Scale-averaged wavelet power was calculated between 0.1 and $0.5 \mathrm{hrs}$, effectively isolating the wave frequencies that were consistently observed following local wind relaxations and reversal of near-bottom currents. The scaleaveraged power also highlights the enhanced variability seen during the diurnal propagation of the front. In general, there is enhanced (weakened) high-frequency variability during periods of strong (weak) water column density stratification. The modulation of the front by the local diurnal wind forcing appears to be a first-order control on high-frequency internal wave activity at this location, as the advection of upwelling shadow waters controls local stratification.

A similar analysis of the near-bottom (1.3 mab) 1-minute averaged kinetic energy [i.e.,

$\left.K E^{\prime}=\frac{1}{2}\left(U^{\prime 2}+V^{\prime 2}+W^{\prime 2}\right)\right]$, reveals the same temporal variability as the density fluctuations at high-frequencies (Figure 9). This suggests that the high-frequency NLIWs may be important for 
local sediment resuspension (e.g., Quaresma et al., 2007), although further observations and measurements of sediment properties are required to verify this mechanism. Theoretical work also suggests that there is likely to be significant exchange between the bottom boundary layer and the main water column (cf. Harnanan et al., 2015).

Figure 9 Location

The largest density fluctuations and near-bottom kinetic energy variability is documented during 17 July, the frontal crossing with the strongest temperature gradients. It is likely that during the extended upwelling, the waters within the bay (i.e., upwelling shadow) were effectively trapped by the regional upwelling jet and resulted in intense warming and stratification (cf. Figure 1a; Woodson et al., 2009). Following the relaxation of the regional winds, these stratified waters propagated poleward as a buoyant plume front due to strong barotropic and baroclinic forcing (Woodson et al., 2009; Washburn et al., 2011). While the record only resolved one regional upwelling cycle, we expect to see the most high-frequency internal activity following periods of extended regional upwelling due to the increased kinetic energy of the buoyant plume front and increased stratification of the trapped upwelling shadow waters. Thus, regional and local upwelling modulates background environmental conditions and can either stimulate or prevent NLIW formation and propagation in the same geographical location. These results highlight the importance of regional scale variability, as well as local forcing and environmental conditions, on the formation of NLIWs in the shallow coastal environment.

Composite day plots of the local wind forcing and background environmental conditions were created by computing each respective quantity centered on each hour of the day (local time, PDT). The regional upwelling dominated period (13 to 15 July) was excluded to isolate frontal 
event variability. Composite averages are highlighted in Figure 10 and confirm the trends described earlier. During the early morning when the local wind forcing is weak, along-shore currents are directed poleward. The local density stratification increases as stratified upwelling shadow waters appear at the mooring site. This increase in stratification also results in an increase in high-frequency internal wave variability. As the local wind forcing strengthens in the early afternoon, the along-shore currents reverse to flow equatorward and a strong near-surface shear develops. Coinciding with this increase in near-surface shear is a subcritical gradient Richardson number region near the surface. As the wind forcing relaxes, the currents return to flow poleward, and the local stratification and high-frequency internal wave variability decrease. The modulation of the front by local diurnal winds appears to control local stratification and high-frequency internal wave activity at this study site.

\section{Figure 10 Location}

\subsection{NLIW Observations}

The rank-ordered packet of NLIWs observed on 17 July 2011, the event with the largest high-frequency density perturbations, is characterized by upper and lower mixed layers with a thick ( 2-5 m) pycnocline (Figure 11). The flow is strongly sheared in the along-shore direction, with the top layer moving equatorward due to the local wind forcing and the bottom layer heading poleward in the direction of the large-scale background current. Examination of the vertical velocity field reveals that convergence (divergence) zones in the leading (trailing) edges of the waves drive large downwelling (upwelling) events. As the current speed in the upper layer of the water column decreases, each subsequent wave in the packet becomes smaller in amplitude. We note that the waves examined are much longer than the ADCP beam spacing so that the measured velocities are valid (cf. Scotti et al., 2005). The leading large-amplitude wave 
(e.g., the initial wave has an amplitude of $\sim 10 \mathrm{~m}$ with a total water depth of $\sim 20 \mathrm{~m}$ and a top layer depth of $\sim 5 \mathrm{~m}$ ) takes the form of a broad, flat-crested trough with isopycnals that are depressed from their upstream height (i.e., an internal wave of depression) and propagates at a speed of $0.3 \mathrm{~m} / \mathrm{s}$ in the negative along-shore direction (i.e., equatorward, $c_{o b s}=-0.3 \mathrm{~m} / \mathrm{s}$ ). Flat crested NLIWs have been computed as solution of the fully nonlinear DJL equation (see Appendix for a discussion of internal wave theory), with their theory discussed by Lamb and Wan (1998). Flat crested waves have also been shown to form during shoaling (Lamb and WarnVarnas, 2015). Based on a comparison of the wave amplitude $(\sim 10 \mathrm{~m})$ to the total water depth $(\sim$ $20 \mathrm{~m}$ ), the initial 2-3 waves in the rank-ordered packet are among some of the largest NLIWs documented on the continental shelf (Figure 11) [cf. Table 1 of Alford et al. (2012)]. We note that the large-amplitude NLIWs observed here are in much shallower waters than the observations reported in Alford et al. (2012).

\section{Figure 11 Location}

It is not surprising that the leading wave is flat-crested while those that trail are closer to the weakly nonlinear KdV "hump" profile (see Appendix for a discussion of internal wave theory). Beginning with small amplitude NLIWs, increasing the available potential energy in the wave generally leads to an increase in amplitude and a decrease in width in agreement with $\mathrm{KdV}$ theory. At some point, however, for many stratifications, a further increase in potential energy leads to a broadening of the wave, with only a small increase in amplitude. For the current observations, the leading wave has by far the most available potential energy and thus can reasonably be expected to be flat crested, while the waves that trail can be expected to be narrower with an amplitude that decreases gradually for the second and third waves, and faster for subsequent waves. A recent example in the literature is provided by the simulations of 
shoaling internal waves in the South China Sea by Lamb and Warn-Varnas (2015; their figures 4, 5, and 7).

Since upwelling fronts are regions of high biological activity due to increased primary production and the aggregation of phytoplankton due to localized convergence (Graham et al. 1992; Ryan et al. 2008; Ryan et al. 2010), the internal wave packets described above can provide a transport mechanism for moving biological material aggregated at the front, such as planktonic larvae, back into the bay. Likewise, the high-frequency variability in the near-bed kinetic energy, presumably due to the NLIWs, may have implications for larval settlement and recruitment since large instantaneous stress events affect the ability of larvae to anchor to the bed (e.g., Crimaldi et al., 2002; Koehl and Hadfield, 2010). The high-frequency variability may also induce sediment resuspension (e.g., Quaresma et al., 2007).

The mean background density $\left(\rho_{b}\right)$ and along-shore velocity $\left(v_{b}\right)$ profiles for the period before the arrival of the wave train $(18: 25$ - 19:15), along with the standard deviation of the profiles over the same period are shown in Figure 12. The period of time was chosen by first computing a running, windowed standard deviation of the density profile and horizontal (i.e., along-shore) current. Subsequently, we chose a period over which the standard deviation was minimized. While the flow never achieves an exact steady state, the standard deviation of both the background current and density profile, both shown as grey-filled regions, can be seen to be quite small. This illustrates the existence of a quasi-steady background state with high shear prior to the wave train.

\section{Figure 12 Location}

The along-shore velocity profiles of the leading waves of the NLIW train are shown in Figure 13. The bottom panels show along-shore velocity profiles of the background ( $v_{b}$, black) 
and total at the wave trough ( $v$, blue) velocities as a function of depth at the wave-trough locations indicated by vertical lines in Figure 13. It can be seen that both waves displayed similar horizontal currents at the wave trough. In particular, the total along-shore velocity profiles at the wave troughs $(v)$ exhibit a single zero-crossing near the mid-depth location $(10 \mathrm{mab})$ and an increase in magnitude (in the negative direction) further up in the water column (i.e., above 10 mab). A similar profile was found for the total velocity at the next five troughs in the NLIW train (not shown). Using different background currents within the grey shaded region of Figure 13 did not affect the profiles

\section{Figure 13 Location}

Analysis of the space-time variability of the NLIW train reveals that the pycnocline region is subject to enhanced levels of velocity shear that lead to periods of subcritical Richardson numbers $(R i<0.25$; Figure 14$)$. The upper portion of the water column is also subject to a combination of wind-driven shear and weak density stratification that leads to large regions with $R i<0.25$. During the passage of the wave train, the band of high shear and region where $R i<0.25$ penetrate deeper into the water column along the pycnocline. This leads to a situation in which the upper portion of the water column is subject to dynamic instabilities (which will rapidly break down into turbulence) while the underlying pycnocline still supports NLIWs for a significant period of time. A number of studies have explored the onset of shear instability in progressive internal waves and have noted that the gradient Richardson number must fall well below the critical value of 0.25 for long enough time periods in order to induce instability (cf. Troy and Koseff, 2005; Barad and Fringer, 2010; Lamb and Farmer, 2011); however, a strong background shear current was not included in the analysis [Lamb and Farmer (2011) included a moderate background current] and waves were assumed to be "clean solitary 
waves" to start while the coastal ocean is a more turbulent environment. Stastna and Walter (2014) explored numerical simulations of the evolution of topographically generated NLIWs and lee waves in the presence of a strong background shear current. They found that a moderate background shear current can lead to a hybrid state in which portions of the water column are rich in short length scale vortices, while the underlying pycncocline and regions below it behave largely as internal wave theory would suggest. However, they also found that a strong enough background shear current could lead to the breakdown of an existing wave train. Further exploration of the role of background shear current in the presence of NLIWs is needed, with rich implications for dynamics (see next section).

\section{Figure 14 Location}

Woodson et al. (2011) documented the presence of rank-ordered packets of NLIWs near the location of the front and hypothesized that variations in the flow field and diurnal windmodulation of the front may be the generation mechanism. The following observations were drawn from a multiple-year time series from low-resolution moorings, as well as ten years of synthetic aperture radar images: the NLIWs were consistently observed in the late evening (2000 - 2300 local time, same as this study), there was an increased prevalence of the waves along the frontal boundary during periods of strong diurnal wind forcing, wave crests were oriented perpendicular to shore (i.e., wave propagating in the along-shore equatorward direction), and the waves were absent poleward and outside of the upwelling front. The aforementioned observations, in addition to the lack of any significant topographic features near the study site, suggest that internal tide propagation and/or tide-topography interactions are not the generation mechanism. Certainly there is observational evidence of internal waves propagating behind the nose of a buoyant plume front (cf. Luketina and Imberger 1987, Figure 13; Nash and Moum 
2005, Figure 1; White and Helfrich 2008), as well as theoretical and numerical studies (e.g., Stastna and Walter, 2014 and the references therein).

Expanding on the work of Woodson et al. (2011), we propose several mechanisms by which the NLIWs may be generated by the front. We note that there may be multiple generation mechanisms and sources. Here, we focus on the documented along-shore equatorward propagating waves (cf. Woodson et al., 2011) observed in the late afternoon (black box in Figure 5). The NLIWs observed prior to this period are the subject of ongoing research (specifically, a third mooring in the cross-shelf direction is needed to assess directionality and the cross-shore evolution). One such generation mechanism is transcritical (resonant) generation, whereby the modulation of the front by the diurnal winds results in a transition from supercritical to subcritical flow, where the criticality of the flow is defined using the frontal propagation speed and the intrinsic internal wave speed (see also Nash and Moum, 2005; White and Helfrich, 2008). We note that this dynamic situation, as well as the precise time and location of wave fission, cannot be verified exactly using the mooring instrument since we are not tracking the front directly (see e.g., Nash and Moum, 2005).

An alternative mechanism for the generation of the large-amplitude NLIW train is that the front itself has disintegrated into an undular bore, which manifests itself as the initial blunt wave of depression and trailing internal waves (see Maxworthy, 1980; Lamb, 1994). We note that the proposed dynamic scenarios require further in-situ observations and direct tracking of the front.

\subsection{NLIW Theory}

Internal waves can be described by a variety of theoretical models (linear, weakly nonlinear, and fully nonlinear). These models have different goals depending on the context in 
which they are applied. The Appendix provides a brief summary of their structure, terminology, goals, and short-comings. In this contribution, we explore the ability of a fully nonlinear model (DJL Equation; Equation A3) to reproduce the observed wave shape and velocity profiles of the initial large-amplitude wave in Figure 11 (17 July). The Appendix provides context for the use of a fully nonlinear model, and the shortcomings of linear and weakly nonlinear theory, for these particularly large-amplitude waves that propagate in the presence of a strong background shear.

Using only the background density field (i.e., background current is initially zero), the solution to the DJL equation yields a solitary wave of depression with a sharp, moderately broad central region (Figure 15ai). The velocity profile at the wave trough resembles that expected for a first baroclinic mode (Figure 15bi) and the water column remains stable (Figure 15ci). To examine the effect of the background shear current, a background current is progressively introduced via Equation A3 by increasing its magnitude to match the observed background velocity profile (Figure 12b). Since the baroclinic vorticity at the wave trough of the computed waves is of the same sign as the vorticity due to the background current (Figure 15b), an increase in the magnitude of the background current reduces the maximum possible wave amplitude (cf. Stastna and Lamb, 2002). However, the upper bound on wave amplitude is difficult to identify in the present case, due to a gradual "wandering" of the numerical algorithm associated with a decreasing gradient Richardson number, or physically with a propensity for shear instability.

\section{Figure 15 Location}

Including the background shear current also yields a solitary wave of depression (Figure 15aii), but with a broader and flatter central region consistent with the observed wave. Figure 15bii shows profiles for the background $\left(v_{b}\right.$, black) and total ( $v$, blue) velocities, respectively, as a function of depth for the largest wave amplitude-current strength combination with which it 
was possible to compute waves. Similar to the field observations, the total velocity at the wave trough shows a single zero-crossing near the mid-depth location and an increase in magnitude (in the negative direction) above the zero-crossing. However, the DJL solver failed to converge when introducing the full background current (Figure 12b) and was only able to produce a solution for less than $50 \%$ of the observed background current (Figure 15bii). The wave shown has a propagation speed that is 1.46 times the linear longwave speed and is thus clearly nonlinear (see further below). Figure 15biii also shows the vertical profile of the gradient Richardson number at the wave trough, indicating a near-surface region of possible shear instability $(\mathrm{Ri}<$ 0.25 , blue curve). It is likely that shear instabilities preclude a full amplitude and current solution to the DJL equation and the associated velocities at the wave trough (see Figures 13 and 15 for the observed and computed amplitude, respectively). A careful contrast of these figures reveals that the DJL solution results in larger near-surface velocity magnitudes at the wave trough relative to the background current, while the observations show decreased near-surface velocity magnitudes relative to the background current. This is possibly due to the fact that the NLIW packet may not be propagating precisely in the equatorward direction, the dynamically evolving nature of the wind forcing, the inability to include the full strength background current in the DJL solution, or a combination of these factors. We also assessed varying angles of wave propagation and adjusted the background current accordingly. The major results described above remained the same, with the exception that some angles of incidence predicted near-surface trapped cores, which were not observed in the field observations.

Nonetheless, the DJL solution with a sheared background current does a better job at reproducing the observed wave shape and the broad-crested central region. A comparison of the wave propagation speed shows that the DJL solution with a background current $(0.19 \mathrm{~m} / \mathrm{s})$ better 
approximates the observed speed $(0.3 \mathrm{~m} / \mathrm{s})$ compared to the DJL solution with no background current $(0.136 \mathrm{~m} / \mathrm{s})$. Note that due to the fact that the background current has a non-zero mean, the scaled down current used for the DJL equation will have a smaller Doppler shift. Based on the observed speed and wave period, the leading wave from the field observations has an approximate wavelength of $470 \mathrm{~m}$. The DJL solution with the background current yields a longer wave (Figure 15aii) that well approximates the observed wavelength compared to the solution with no background current (Figure 15ai). These results highlight the importance of the background current and strong nonlinearities in determining the wave structure and speed.

The combination of the measured profiles shown in Figure 13, and the breakdown of the DJL solution for currents stronger than the one used in Figure 15ii suggest the possible development of critical layers in the flow. The theory of critical layers is briefly reviewed in the Appendix, however the recent simulations of Stastna and Walter (2014) suggest that classical critical layer theory does not have a clear and unambiguous expression in time dependent simulations of wave generation and propagation. In the case of the field measurements it is quite possible that the turbulence in the near surface region completely masks the development of critical layers.

For the interpretation of field data there are two key effects that merit discussion. The first is the inability of a steady theory to describe situations in which a nearly steady wave interacts with local patches of turbulence. Consider a large-amplitude solitary wave propagating in quiescent water when a wind begins to blow and a stress is applied. The near surface region is forced to move by the wind and a surface-trapped, shear current results. Since the wave has substantial energy it may not breakdown completely, but may coexist (at least for some time) with a region undergoing shear instability and enhanced turbulence. This scenario, while 
reasonable conceptually, cannot be described by the DJL equation which assumes a steady wave form (in a frame moving with the wave). The second, related phenomenon is the change in the structure of the vertical profiles of horizontal currents. Modal structure is based on theory without a background shear, so that a mode-1 wave induces positive (negative) currents above (below) the pycnocline, while a mode-2 wave induces two regions of either positive or negative currents (depending on polarity). However, in the situation of a particular wave mode interacting with a dynamically evolving flow field (e.g., surface trapped shear current due to variable wind forcing), horizontal currents at the wave trough may exhibit departures from conventional modal shapes, especially in the near surface region. Indeed, existing theory does not allow for the interpretation of horizontal currents at the wave trough with respect to conventional modal shapes when there is a sufficiently strong background shear current present. In practice, these deviations are likely to be associated with enhanced turbulence (as in the middle panel of our Figure 14b).

The question of how ISWs interact with a background shear current remains an ongoing challenge in internal wave theory and observations (see Stastna and Walter, 2014 and the references therein). There are an increasing number of field observations documenting the modification of NLIWs in the presence of a background shear current, with substantial implications for the development and fate of the waves (e.g., Wang and Pawlowicz, 2011; Lien et al., 2012). Stastna and Walter (2014) showed that a surface-trapped background shear current can lead to the formation of large regions of high vorticity, but that this vorticity only led to moderate perturbations of the underlying pycnocline. The background shear current thus can lead to a hybrid state in which a portion of the water column is rich in short length scale vortices, while the underlying pycnocline maintains large-amplitude internal solitary waves, allowing an 
instability and wave to co-exist for periods of time. They also showed that when the background shear is large enough, possibly such as in the observations presented here, the shear may lead to the breakdown of the existing wave train. We refer the reader to Stastna and Walter (2014) for more details.

Overall, even the mathematically most complete theory of internal waves is only a guide to interpreting observations. Based on the measurements presented above, one could speculate that an entire class of internal wave models that account for fluid turbulence in portions of the water column and strong background shear await the attention of the applied mathematics community. Indeed, only such models can be considered truly appropriate for the shallower waters in the coastal region and the waves presented in this manuscript.

Figure 16 highlights the evolution of the NLIW train between FDN and FDS $(\sim 220 \mathrm{~m}$ apart). Over a relatively short distance, the wave train evolves substantially leading to marked changes in the size and shape of individual waves, although the leading waves remain largely coherent. The observations at FDS suggest an apparent thickening of the pycnocline relative to FDN. These results suggest that the presence of shear instabilities may drive active mixing in the stratified interior that can in turn alter internal wave dynamics. Further field-motivated simulations that consider the detailed dynamics of particular background stratification, current (shear), and forcing combinations are needed in order to better understand the time evolution of the wave features. The authors are currently exploring stratified adjustment simulations, and the results of these will be reported elsewhere. Additional in-situ observations of similar internal waves, and in particular Lagrangian observations with turbulence measurements, are also warranted.

\section{Figure 16 Location}




\section{Conclusions}

Discussion of the role of NLIWs in the shallow $(\sim 20 \mathrm{~m})$, nearshore environment has been mainly speculative, and many questions still remain with respect to the evolution, fate, and impact of NLIWs in this biologically productive region. We present high-resolution observations of large-amplitude internal waves in the shallow coastal environment of northern Monterey Bay, CA. The NLIWs are observed at a persistent front that forms between the recently upwelled waters and warmer stratified waters that are trapped in the bay (upwelling shadow). The front propagates up and down the coast in the along-shore direction as a buoyant plume front due to modulation by strong diurnal wind forcing. In this contribution, we demonstrate how a combination of regional-scale upwelling and local diurnal wind forcing are key components controlling local stratification and the formation of internal wave guides that allow for highfrequency internal wave activity. We also show that existing theoretical models for solitary internal waves cannot accurately describe the largest NLIWs observed during periods exhibiting large background shear.

The shape of the coastline is likely important for both the oceanic and atmospheric dynamics that contribute to the NLIW formation and development. The upwelling point north of the bay drives a cold water jet across the warm upwelling shadow within the bay, while the coastline within the bay drives the strong diurnal wind forcing due to daily heating and cooling of the adjacent land surfaces. The coastline orientation is a necessary factor for the modulation of the buoyant plume front by diurnal winds and potentially the release of internal waves. This dynamic situation exists all along the California Current Large Marine Ecosystem (CCLME), but is by no means geographically unique, being present in other eastern boundary currents and "upwelling shadow" systems [e.g., Peru-Chile Current System, Benguela Current System, see 
Graham and Largier, (1997)]. Thus, the modulation of coastal upwelling fronts by diurnal winds and the subsequent formation and evolution of NLIWs at the front may be realized in coastal upwelling systems around the world. These NLIWs are expected to dramatically alter the coastal physical environment with important ecological implications. Further observational and numerical efforts are needed to better understand this system, as well as the extension of the results to other upwelling systems and over the entire upwelling season (cf. Garcia-Reyes and Larger, 2012).

\section{Acknowledgements}

This work was supported by the National Science Foundation (NSF) Physical Oceanography program through grants OCE-0824972 and OCE-0926340. Marek Stastna is supported by the Natural Sciences and Engineering Research Council of Canada. We acknowledge Bill Smyth for providing TG code; John Ryan for SST satellite photos; and Leif Thomas, Derek Fong, Oliver Fringer, and Jeffrey Koseff for helpful discussions. This manuscript greatly benefited from suggestions by two anonymous reviewers. Bathymetry data used in this study were acquired, processed, archived, and distributed by the Seafloor Mapping Lab of California State University Monterey Bay.

\section{Appendix: Internal Wave Theory}

Internal waves can be described by a variety of theoretical models. These models have different goals depending on the context in which they are applied. This Appendix provides a brief summary of their structure, their terminology, goals and short-comings. Linear theory, through the Taylor-Goldstein (TG) equation, can yield estimates of the intrinsic phase speed of waves in the presence of an ambient current (cf. Nash and Moum, 2005). The TG equation considers normal mode perturbations to a stratified, parallel shear flow, and with the boundary 
conditions $[\hat{\psi}(z=0)=\hat{\psi}(z=H)=0]$, its eigenvalues and eigenfunctions provide the linear phase velocity $\left(c_{\text {linear }}\right)$ and vertical structure function $(\hat{\psi})$, respectively, of a linear disturbance,

$$
\frac{d^{2} \hat{\psi}}{d z^{2}}+\left[\frac{N^{2}}{\left(V-c_{\text {linear }}\right)^{2}}-\frac{V_{z z}}{\left(V-c_{\text {linear }}\right)}-k^{2}\right] \hat{\psi}=0 .
$$

Here $N^{2}(z)$ and $V(z)$ are calculated using the mean background density $\left(\rho_{b}\right)$ and along-shore velocity $\left(v_{b}\right)$ profiles prior to the initial wave, respectively; $k$ represents the horizontal (i.e., along-shore) wavenumber; and the stream function is given by $\psi=\hat{\psi}(z) e^{i k\left(x-c_{\text {linear }} t\right)}$.

Linear theory provides no information about wave amplitude since, formally, a wave of any amplitude is a solution to the linear problem. The TG equation breaks down when $V-$ $c_{\text {linear }}=0$ at some point in the water column. The region near the value of $z$ where this occurs is called a critical layer. Linear theory has been augmented to include critical layers (Maslowe and Redekopp, 1982) though recent nonlinear simulations (Stastna and Walter, 2014) demonstrate that the finite amplitude picture is more complex than the linear theory might suggest. In the absence of critical layers, linear theory provides a good leading order estimate of wave speed. However, TG theory only yields qualitative information about the vertical structure of the waveinduced currents, and provides no information about the horizontal structure of the waves. Weakly nonlinear theories improve significantly on the latter shortcoming, but still rely on the TG equation to provide an estimate of vertical structure.

Weakly nonlinear theories are derived by perturbation expansions of the governing equations in small parameters such as the wave amplitude and aspect ratio, and lead to the Korteweg-de Vries (KdV) family of equations for the horizontal structure of the waves. Including cubic nonlinearity yields the so-called extended KdV (eKdV):

$$
\eta_{t}+\left(c_{\text {linear }}+\alpha_{1} \eta+\alpha_{2} \eta^{2}\right) \eta_{x}+\beta_{1} \eta_{x x x}=0,
$$


where $\eta(x, t)$ is the isopycnal vertical displacement and the coefficients $\alpha_{1}, \alpha_{2}$, and $\beta_{1}$ are functions of the steady background stratification and shear through the linear eigenmode $(\hat{\psi})$ of interest in the TG equation (cf. Helfrich and Melville, 2006; Lamb and Yan, 1996). By looking for exact traveling wave solutions of these equations it is possible to make predictions of wave shapes of different amplitudes, along with estimates of the increase in propagation speed due to finite amplitude effects. We refer the reader to Helfrich and Melville (2006) for a detailed review of weakly nonlinear theories.

The central weakness of weakly nonlinear theories is the lack of an a priori error bound on their domain of applicability. Historically this has meant that weakly nonlinear theory is augmented when qualitative discrepancies with observations are identified. An example of this is the observation that while the KdV theory predicts larger amplitude waves are narrow, large waves are often observed to be blunt, or even flat-crested. The Gardner, or mKdV, theory addresses this discrepancy by keeping two terms in the amplitude parameter, though its predictions are unreliable when the main pycnocline is centered well away from the boundary.

Despite their utility in reaching qualitative conclusions, weakly nonlinear theories are well known to have difficulty in quantitatively representing vertical profiles of wave-induced currents (Lamb and Yan, 1996; Lamb, 1999; Stastna and Peltier, 2005) when the wave amplitude is large, as is clearly the case for the observed waves discussed above. This misfit between observed wave structure and that predicted by weakly nonlinear theory has not stopped the extension of $\mathrm{KdV}$ type models to the case of spatially varying depth, and environmental parameters, though for reasons of brevity we do not discuss such models herein [see the recent work by Lamb and Xiao (2014) for detailed discussion and references]. 
Fully nonlinear theory can provide more details about how shear modifies the largeamplitude waves. It is possible to reduce the stratified Euler equations to a single equation by making an assumption about the solution form (e.g., a traveling wave of permanent form). The resulting equation is called the Dubreil-Jacotin-Long (DJL) equation after the authors who originally derived it. The DJL equation describes internal solitary waves (ISW) and is equivalent to the full set of stratified Euler equations, for this reason it is often referred to as the "exact theory". While the real ocean is most certainly viscous (and often turbulent), solitary waves are only possible when energy is conserved and hence the label "exact" is reasonable when compared to the maze of terminology found in the nonlinear waves literature. When a background shear current, $V(z)$, is included, the DJL equation reads (e.g., Stastna and Lamb, 2002):

$$
\nabla^{2} \eta+\frac{V^{\prime}(z-\eta)}{c-V(z-\eta)}\left[\eta_{x}^{2}+\left(1-\eta_{z}\right)^{2}-1\right]+\frac{N^{2}(z-\eta)}{[c-V(z-\eta)]^{2}} \eta=0,
$$

where $\eta(x, z)$ is the so-called isopycnal displacement, or the displacement of an isopycnal from its upstream location. The DJL is subject to the boundary conditions,

$$
\eta(x, 0)=\eta(x, H)=0 \text { and } \lim _{x \rightarrow \pm \infty} \eta(x, z)=0 .
$$

While the DJL equation has no known exact solution (except for the somewhat trivial case of a linear stratification with no background shear current), numerical solutions of the DJL equation have been successfully used to match vertical profiles of wave-induced velocities in simulations of resonantly generated waves (Lamb, 1999; Stastna and Peltier 2004, 2005). While different numerical techniques have been developed for the DJL equation, the variational formulation (Turkington et al. 1991) extended to include background shear currents (Stastna and Lamb, 2002), has a publically available MATLAB implementation of the solver (Dunphy et al. 2011). This is the tool we have employed for the calculations presented in this manuscript. 

amplitude, with the upper bound given by either the onset of breaking (i.e., overturning isopycnals), wave broadening to the so-called conjugate flow, or the onset of shear instability. Stastna and Lamb (2002) discuss in detail some of the counter intuitive effects that the presence of a background shear current has on internal waves.

\section{References}

Alford, M., Mickett, J., Zhang, S., MacCready, P., Zhao, Z., Newton, J., 2012. Internal Waves on the Washington Continental Shelf. Oceanography. doi:10.5670/oceanog.2012.43

Barad, M.F., Fringer, O.B., 2010. Simulations of shear instabilities in interfacial gravity waves. J. Fluid Mech. 644, 61. doi:10.1017/S0022112009992035

Boehm, A.B., Sanders, B.F., Winant, C.D., 2002. Cross-shelf transport at Huntington Beach. Implications for the fate of sewage discharged through an offshore ocean outfall. Environ. Sci. Technol. 36, 1899-1906. doi:10.1021/es0111986

Booth, J.A.T., McPhee-Shaw, E.E., Chua, P., Kingsley, E., Denny, M., Phillips, R., Bograd, S.J., Zeidberg, L.D., Gilly, W.F., 2012. Natural intrusions of hypoxic, low pH water into nearshore marine environments on the California coast. Cont. Shelf Res. 45, 108-115. doi:10.1016/j.csr.2012.06.009

Bourgault, D., Blokhina, M.D., Mirshak, R., Kelley, D.E., 2007. Evolution of a shoaling internal solitary wavetrain. Geophys. Res. Lett. 34. doi:10.1029/2006GL028462

Cheriton, O.M., McPhee-Shaw, E.E., Shaw, W.J., Stanton, T.P., Bellingham, J.G., Storlazzi, C.D., 2014. Suspended particulate layers and internal waves over the southern Monterey Bay continental shelf: An important control on shelf mud belts? J. Geophys. Res. Ocean. 119, 428-444. doi:10.1002/2013JC009360

Cheriton, O.M., McPhee-Shaw, E.E., Storlazzi, C.D., Rosenberger, K.J., Shaw, W.J., Raanan, B.Y., 2014. Upwelling rebound, ephemeral secondary pycnoclines, and the creation of a near-bottom wave guide over the Monterey Bay continental shelf. Geophys. Res. Lett. 41, 2014GL061897. doi:10.1002/2014GL061897

Crimaldi, J.P., Thompson, J.K., Rosman, J.H., Lowe, R.J., Koseff, J.R., 2002. Hydrodynamics of larval settlement: The influence of turbulent stress events at potential recruitment sites. Limnol. Oceanogr. doi:10.4319/1o.2002.47.4.1137 
Davis, K.A., Leichter, J.J., Hench, J.L., Monismith, S.G., 2008. Effects of western boundary current dynamics on the internal wave field of the Southeast Florida shelf. J. Geophys. Res. Ocean. 113, C09010. doi:10.1029/2007JC004699

DeCarlo, T.M., Karnauskas, K.B., Davis, K.A., Wong, G.T.F. 201. Climate modulates internal wave activity in the Northern South China Sea. Geophys Res Lett 42:831-838

Drake, P.T., McManus, M.A., Storlazzi, C.D., 2005. Local wind forcing of the Monterey Bay area inner shelf. Cont. Shelf Res. 25, 397-417. doi:10.1016/j.csr.2004.10.006

Dunphy, M., Subich, C., Stastna, M., 2011. Spectral methods for internal waves: Indistinguishable density profiles and double-humped solitary waves. Nonlinear Process. Geophys. 18, 351-358. doi:10.5194/npg-18-351-2011

Emery, W.J., Thomson, R.E., 2001. Data Analysis Methods in Physical Oceanography. Second and Revised Edition, Marine Ecology Progress Series [Mar. Ecol. Prog. Ser.].

Farge, M., 1992. Wavelet Transforms And Their Applications To Turbulence. Annu. Rev. Fluid Mech. doi:10.1146/annurev.fluid.24.1.395

García-Reyes, M., Largier, J.L., 2012. Seasonality of coastal upwelling off central and northern California: New insights, including temporal and spatial variability. J. Geophys. Res. doi:10.1029/2011JC007629

Graham, W.M., Field, J.G., Potts, D.C., 1992. Persistent "upwelling shadows" and their influence on zooplankton distributions. Mar. Biol. 114, 561-570. doi:10.1007/BF00357253

Graham, W.M., Largier, J.L., 1997. Upwelling shadows as nearshore retention sites: The example of northern Monterey Bay. Cont. Shelf Res. 17, 509-532. doi:10.1016/S02784343(96)00045-3

Hall, R.A., Alford, M.H., Carter, G.S., Gregg, M.C., Lien, R.C., Wain, D.J., Zhao Z (2014) Transition from partly standing to progressive internal tides in Monterey Submarine Canyon. Deep Res Part II Top Stud Oceanogr 104:164-173

Harnanan, S., Soontiens, N., Stastna, M., 2015. Internal wave boundary layer interaction: A novel instability over broad topography. Phys. Fluids 27, -. doi:http://dx.doi.org/10.1063/1.4906299

Helfrich, K.R., Melville, W.K., 2006. LONG NONLINEAR INTERNAL WAVES. Annu. Rev. Fluid Mech. doi:10.1146/annurev.fluid.38.050304.092129

Hosegood, P., Van Haren, H., 2004. Near-bed solibores over the continental slope in the FaeroeShetland Channel, in: Deep-Sea Research Part II: Topical Studies in Oceanography. pp. 2943-2971. doi:10.1016/j.dsr2.2004.09.016 
Jackson, C.R., da Silva, J.C.B., Jeans, G., 2012. The generation of nonlinear internal waves. Oceanography $25,108-123$.

Klymak, J.M., 2003. Internal solitary waves of elevation advancing on a shoaling shelf. Geophys. Res. Lett. doi:10.1029/2003GL017706

Koehl, M.A.R., Hadfield, M.G., 2010. Hydrodynamics of larval settlement from a larva's point of view, in: Integrative and Comparative Biology. pp. 539-551. doi:10.1093/icb/icq101

Lamb, K.G., 2014. Internal Wave Breaking and Dissipation Mechanisms on the Continental Slope/Shelf. Annu. Rev. Fluid Mech. 46, 231-254. doi:10.1146/annurev-fluid-011212140701

Lamb, K.G., 1999. Theoretical descriptions of shallow-water solitary internal waves: Comparisons with fully-nonlinear waves, in: The 1998 WHOIMOS $\backslash O N R$ Internal Solitary Wave Workshop: Contributed Papers, Tech. Rep. WHOI-99-07,, Edited by T. F. Duda and D. M. Farmer, WHOI-99-07. Woods Hole, Mass.

Lamb, K.G., 1994. Numerical experiments of internal wave generation by strong tidal flow across a finite amplitude bank edge. J. Geophys. Res., 99, 843-864.

Lamb, K.G., Warn-Varnas, A., 2015. Two-dimensional numerical simulations of shoaling internal solitary waves at the ASIAEX site in the South China Sea. Nonlin. Processes Geophys. 22, 289-312. Doi:10.5194/npg-22-289-2015.

Lamb, K.G., Xiao, W. 2014. Internal solitary waves shoaling onto a shelf: Comparisons of weakly-nonlinear and fully nonlinear models for hyperbolic-tangent stratifications. Ocean Modeling. 78, 17-34

Lamb, K.G., Farmer, D., 2010. Instabilities in an Internal Solitary-like Wave on the Oregon Shelf. J. Phys. Oceanogr. 41, 67-87. doi:10.1175/2010JPO4308.1

Lamb, K.G., Yan, L., 1996. The Evolution of Internal Wave Undular Bores: Comparisons of a Fully Nonlinear Numerical Model with Weakly Nonlinear Theory. J. Phys. Oceanogr. 26, 2712-2734. doi:10.1175/1520-0485(1996)026<2712:TEOIWU>2.0.CO;2

Lamb, K.G., Wan, B., 1998. Conjugate flows and flat solitary waves for a continuously stratified fluid. Phys. Fluids. 10, 2061-2079.

Large, W.G., Pond, S., 1981. Open Ocean Momentum Flux Measurements in Moderate to Strong Winds. J. Phys. Oceanogr. doi:10.1175/1520-0485(1981)011<0324:OOMFMI>2.0.CO;2

Leichter, J.J., Wing, S.R., Miller, S.L., Denny, M.W., 1996. Pulsed delivery of subthermocline water to Conch Reef (Florida Keys) by internal tidal bores. Limnol. Oceanogr. doi:10.4319/lo.1996.41.7.1490 
Lien, R.-C., D’Asaro, E.A., Henyey, F., Chang, M.-H., Tang, T.-Y., Yang, Y.-J., 2012. Trapped Core Formation within a Shoaling Nonlinear Internal Wave. J. Phys. Oceanogr. doi:10.1175/2011JPO4578.1

Luketina, D.A., Imberger, J., 1987. Characteristics of a surface buoyant jet. J. Geophys. Res. doi:10.1029/JC092iC05p05435

Maxworthy, T., 1980. On the formation of nonlinear internal waves from the gravitational collapse of mixed regions in two and three dimensions. J. Fluid Mech., 96, 47-64.

Moum, J.N., Farmer, D.M., Smyth, W.D., Armi, L., Vagle, S., 2003. Structure and Generation of Turbulence at Interfaces Strained by Internal Solitary Waves Propagating Shoreward over the Continental Shelf. J. Phys. Oceanogr. doi:10.1175/15200485(2003)033<2093:SAGOTA>2.0.CO;2

Nash, J.D., Moum, J.N., 2005. River plumes as a source of large-amplitude internal waves in the coastal ocean. Nature 437, 400-403. doi:10.1038/nature03936

Nidzieko, N.J., Fong, D.A., and Hench, J.L., 2006, Comparison of Reynolds stress estimates derived from standard and fast-ping ADCPs, J. Atmos. Oceanic Technol., 23, 854-861, doi:10.1175/JTECH1885.1.

Pineda, J., 1999. Circulation and larval distribution in internal tidal bore warm fronts. Limnol. Oceanogr. doi:10.4319/lo.1999.44.6.1400

Pineda, J., 1994. Internal tidal bores in the nearshore: Warm-water fronts, seaward gravity currents and the onshore transport of neustonic larvae. J. Mar. Res.

doi: $10.1357 / 0022240943077046$

Pineda, J., 1991. Predictable upwelling and the shoreward transport of planktonic larvae by internal tidal bores. Science 253, 548-549. doi:10.1126/science.253.5019.548

Quaresma, L.S., Vitorino, J., Oliveira, A., da Silva, J., 2007. Evidence of sediment resuspension by nonlinear internal waves on the western Portuguese mid-shelf. Mar. Geol. 246, 123-143. doi:10.1016/j.margeo.2007.04.019

Rosenfeld, L., Shulman, I., Cook, M., Paduan, J., Shulman, L., 2009. Methodology for a regional tidal model evaluation, with application to central California. Deep. Res. Part II Top. Stud. Oceanogr. 56, 199-218. doi:10.1016/j.dsr2.2008.08.007

Rosenfeld, L.K., Schwing, F.B., Garfield, N., Tracy, D.E., 1994. Bifurcated flow from an upwelling center: a cold water source for Monterey Bay. Cont. Shelf Res. doi:10.1016/0278-4343(94)90058-2 
Ryan, J.P., Fischer, A.M., Kudela, R.M., McManus, M.A., Myers, J.S., Paduan, J.D., Ruhsam, C.M., Woodson, C.B., Zhang, Y., 2010. Recurrent frontal slicks of a coastal ocean upwelling shadow. J. Geophys. Res. Ocean. 115. doi:10.1029/2010JC006398

Ryan, J.P., McManus, M.A., Paduan, J.D., Chavez, F.P., 2008. Phytoplankton thin layers caused by shear in frontal zones of a coastal upwelling system. Mar. Ecol. Prog. Ser. 354, 21-34. doi: $10.3354 /$ meps07222

Sandstrom, H., Elliott, J.A., 1984. Internal tide and solitons on the Scotian Shelf: A nutrient pump at work. J. Geophys. Res. Ocean. 89, 6415-6426. doi:10.1029/JC089iC04p06415

Scotti, A., Butman, B., Beardsley, R.C., Alexander, P.S., Anderson, S., 2005. A modified beamto-earth transformation to measure short-wavelength internal waves with an acoustic Doppler current profiler. J. Atmos. Ocean. Technol. 22, 583-591. doi:10.1175/JTECH1731.1

Scotti, A., Pineda, J., 2004. Observation of very large and steep internal waves of elevation near the Massachusetts coast. Geophys. Res. Lett. 31, 1-5. doi:10.1029/2004GL021052

Smyth, W.D., Moum, J.N., Nash, J.D., 2010. Narrowband Oscillations in the Upper Equatorial Ocean. Part II: Properties of Shear Instabilities. J. Phys. Oceanogr. 41, 412-428. doi:10.1175/2010JPO4451.1

Stastna, M., Lamb, K.G., 2002. Large fully nonlinear internal solitary waves: The effect of background current. Phys. Fluids.

Stastna, M., Peltier, W.R., 2005. On the resonant generation of large-amplitude internal solitary and solitary-like waves. J. Fluid Mech. 543, 267. doi:10.1017/S002211200500652X

Stastna, M., Peltier, W.R., 2004. Upstream-propagating solitary waves and forced internal-wave breaking in stratified flow over a sill. Proc. R. Soc. A Math. Phys. Eng. Sci. doi:10.1098/rspa.2004.1316

Stastna, M., Walter, R., 2014. Transcritical generation of nonlinear internal waves in the presence of background shear flow. Phys. Fluids 26, 086601. doi:10.1063/1.4891871

Suanda, S.H., Barth, J.A., Holman, R.A., Stanley, J., 2014. Shore-Based Video Observations of Nonlinear Internal Waves across the Inner Shelf *,+. J. Atmos. Ocean. Technol. 31, 714 728. doi:10.1175/JTECH-D-13-00098.1

Suanda, S.H., Barth, J.A., Woodson, C.B., 2011. Diurnal heat balance for the northern Monterey Bay inner shelf. J. Geophys. Res. Ocean. 116. doi:10.1029/2010JC006894

Torrence, C., Compo, G.P., 1998. A Practical Guide to Wavelet Analysis. Bull. Am. Meteorol. Soc. 79, 61-78. doi:10.1175/1520-0477(1998)079<0061:APGTWA>2.0.CO;2 
Troy, C.D., Koseff, J.R., 2005. The instability and breaking of long internal waves. J. Fluid Mech. doi:10.1017/S0022112005006798

Turkington, B., Eydeland, A., Wang, S., 1991. A Computational Method for Solitary Internal Waves in a Continuously Stratified Fluid. Stud. Appl. Math. 85, 93-127.

Van Haren, H., Gostiaux, L., Laan, M., van Haren, M., van Haren, E., Gerringa, L.J.A., 2012. Internal wave turbulence near a texel beach. PLoS One 7. doi:10.1371/journal.pone.0032535

Venayagamoorthy, S.K., Fringer, O.B., 2007. On the formation and propagation of nonlinear internal boluses across a shelf break. J. Fluid Mech. 577, 137. doi:10.1017/S0022112007004624

Walter, R.K., 2014. Nonlinear internal waves, internal bores, and turbulent mixing in the nearshore coastal environment, PhD Thesis, Civil and Environmental Engineering, Stanford University.

Walter, R.K., Brock Woodson, C., Arthur, R.S., Fringer, O.B., Monismith, S.G., 2012. Nearshore internal bores and turbulent mixing in southern Monterey Bay. J. Geophys. Res. Ocean. 117. doi:10.1029/2012JC008115

Walter, R.K., Nidzieko, N.J., Monismith, S.G., 2011. Similarity scaling of turbulence spectra and cospectra in a shallow tidal flow. J. Geophys. Res. Ocean. 116, 1-14. doi:10.1029/2011JC007144

Walter, R.K., Squibb, M.E., Woodson, C.B., Koseff, J.R., Monismith, S.G., 2014a. Stratified turbulence in the nearshore coastal ocean: Dynamics and evolution in the presence of internal bores. J. Geophys. Res. Ocean. 119, 8709-8730. doi:10.1002/2014JC010396

Walter, R.K., Woodson, C.B., Leary, P.R., Monismith, S.G., 2014b. Connecting wind-driven upwelling and offshore stratification to nearshore internal bores and oxygen variability. J. Geophys. Res. Ocean. 119, 3517-3534. doi:10.1002/2014JC009998

Wang, C., Pawlowicz, R., 2011. Propagation speeds of strongly nonlinear near-surface internal waves in the Strait of Georgia. J. Geophys. Res. Ocean. 116. doi:10.1029/2010JC006776

Wang, X., Chao, Y., Dong, C., Farrara, J., Li, Z., McWilliams, J.C., Paduan, J.D., Rosenfeld, L.K., 2009. Modeling tides in Monterey Bay, California. Deep. Res. Part II Top. Stud. Oceanogr. 56, 219-231. doi:10.1016/j.dsr2.2008.08.012

Washburn, L., Fewings, M.R., Melton, C., Gotschalk, C., 2011. The propagating response of coastal circulation due to wind relaxations along the central California coast. J. Geophys. Res. Ocean. 116. doi:10.1029/2011JC007502 
White, B.L., Helfrich, K.R., 2008. Gravity currents and internal waves in a stratified fluid. J. Fluid Mech. 616, 327-356. doi:10.1017/S0022112008003984

Wong, S.H.C., Santoro, A.E., Nidzieko, N.J., Hench, J.L., Boehm, A.B., 2012. Coupled physical, chemical, and microbiological measurements suggest a connection between internal waves and surf zone water quality in the Southern California Bight. Cont. Shelf Res. 34, 64-78. doi:10.1016/j.csr.2011.12.005

Woodson, C.B., Barth, J.A., Cheriton, O.M., McManus, M.A., Ryan, J.P., Washburn, L., Carden, K.N., Cheng, B.S., Fernandes, J., Garske, L.E., Gouhier, T.C., Haupt, A.J., Honey, K.T., Hubbard, M.F., Iles, A., Kara, L., Lynch, M.C., Mahoney, B., Pfaff, M., Pinsky, M.L., Robart, M.J., Stewart, J.S., Teck, S.J., True, A., 2011. Observations of internal wave packets propagating along-shelf in northern Monterey Bay. Geophys. Res. Lett. 38. doi:10.1029/2010GL045453

Woodson, C.B., Washburn, L., Barth, J.A., Hoover, D.J., Kirincich, A.R., McManus, M.A., Ryan, J.P., Tyburczy, J., 2009. Northern Monterey Bay upwelling shadow front: Observations of a coastally and surface-trapped buoyant plume. J. Geophys. Res. Ocean. 114. doi:10.1029/2009JC005623

Zhao, Z., Alford, M.H., Lien, R.-C., Gregg, M.C., Carter, G.S., 2012. Internal tides and mixing in a submarine canyon with time-varying stratification. J. Phys. Oceanogr.

doi:10.1175/JPO-D-12-045.1 
1

2

3

4

5

6

7

8

9

10

11

12

13

14

15

16

17

18

19

20

21

22

23

24

25

26

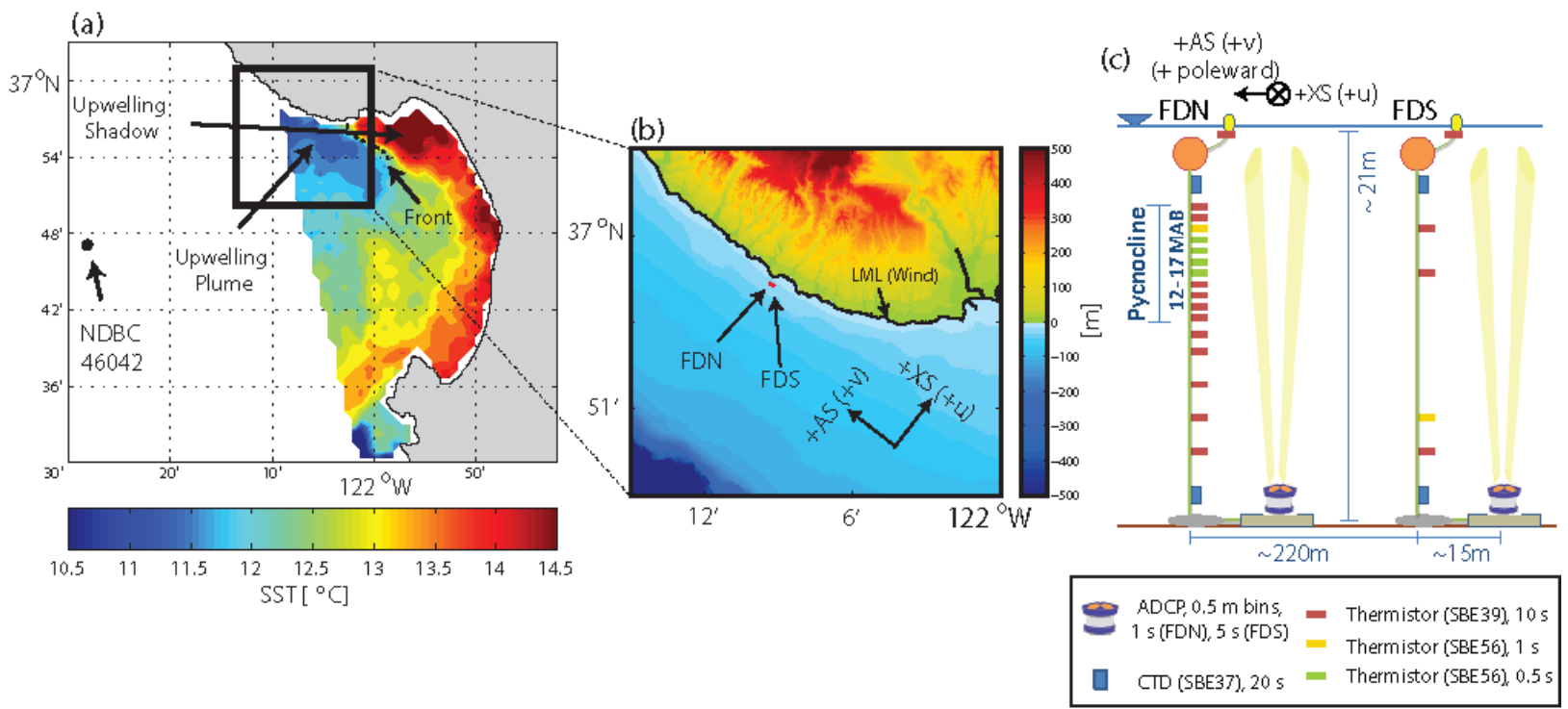

Figure 1: (a) AVHHR SST image from 14 July 2011, 04:56:00 GMT highlighting the upwelling plume, upwelling "shadow," front location (dashed line), offshore NDBC 46042 buoy (black circle), and nearshore study site (black box). (b) Bathymetry and topography of the study site with mooring locations (red dots). (c) Experimental setup showing mooring and instrument configuration. 


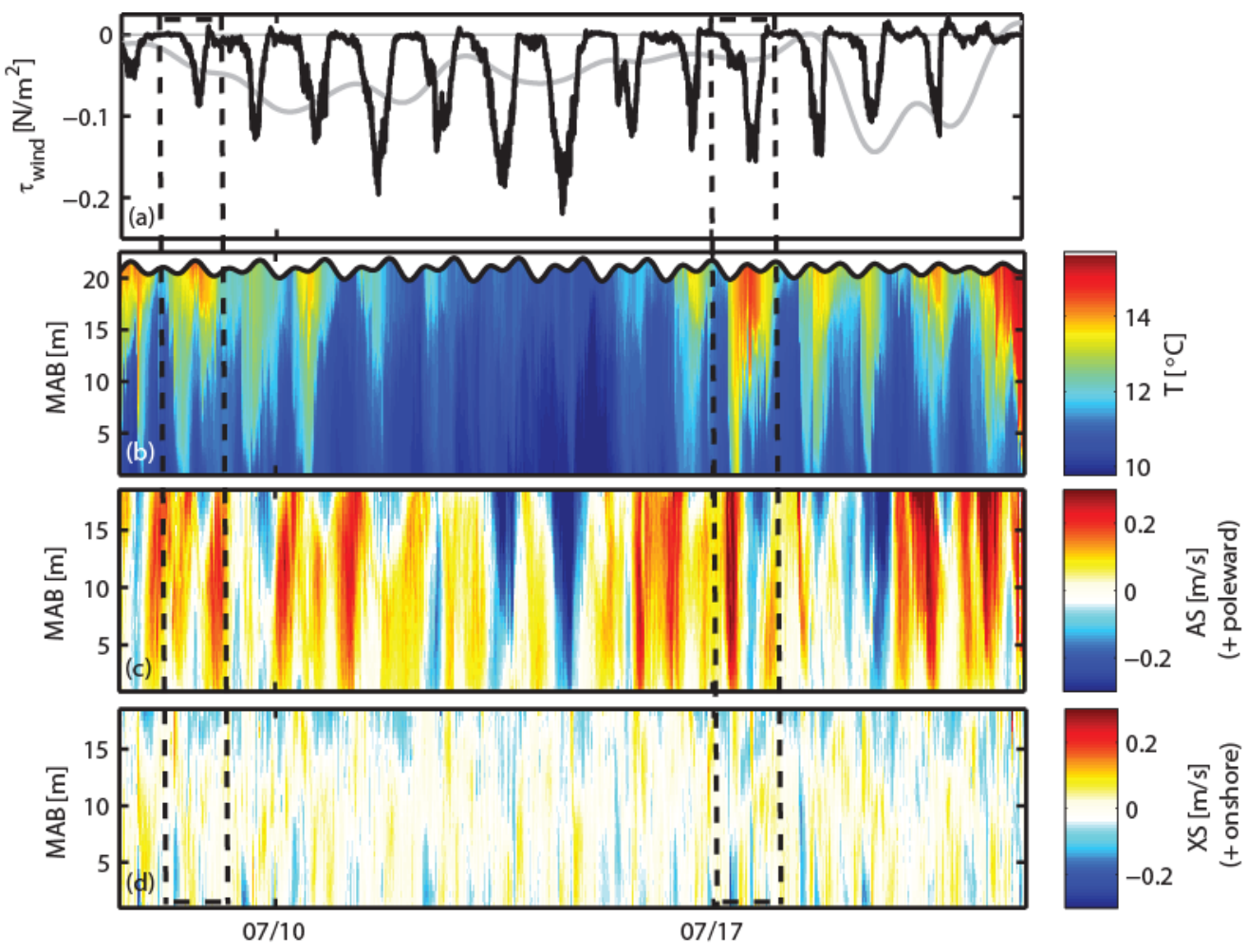

Figure 2: Time series during the entire study period of the (a) local (black) and regional (grey, 33 hr low-pass filtered) along-shore wind stress (positive poleward). (b) Temperature, (c) alongshore velocity (positive poleward), and (c) cross-shore velocity (positive onshore) vertical contour plots at FDN. The location of the ocean surface is denoted in panel (b) by a black line. The dashed black boxes denote the time periods in Figures 5 and 6. 

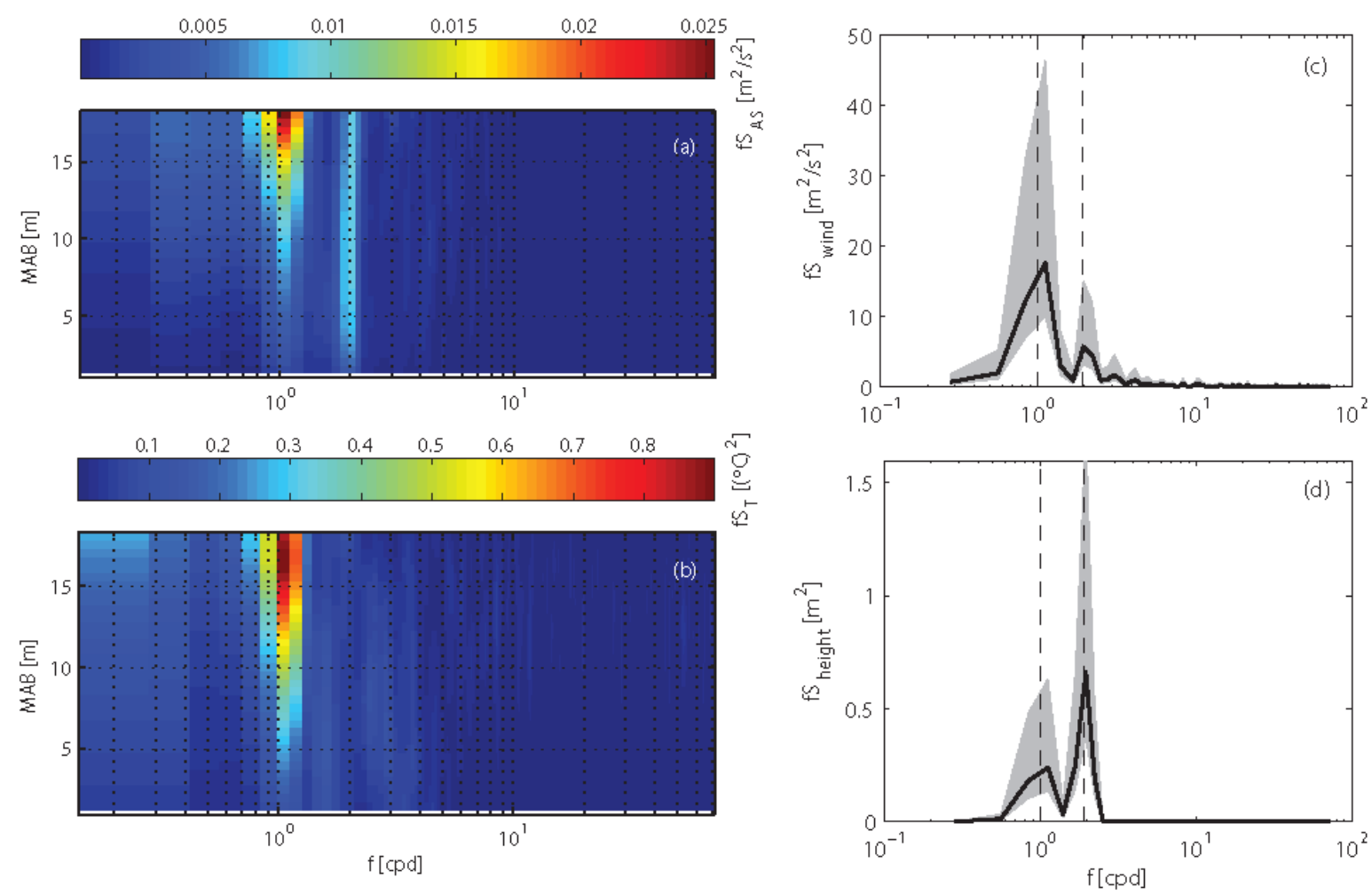

Figure 3: Variance preserving power spectra over the entire study period of the (a) along-shore velocity across all depths, (b) temperature across all depths, (c) local along-shore winds, and (d) free-surface height. The dashed black lines in panels (c) and (d) denote the diurnal and semidiurnal ( $\mathrm{M}_{2}$ tidal component) frequencies, and the grey shading represents the $80 \%$ confidence interval. 


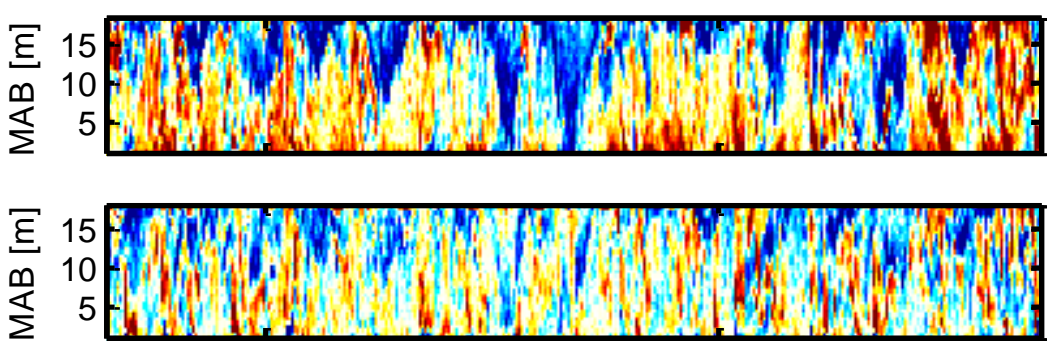

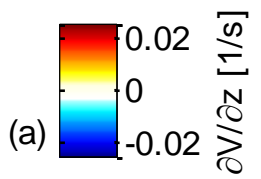

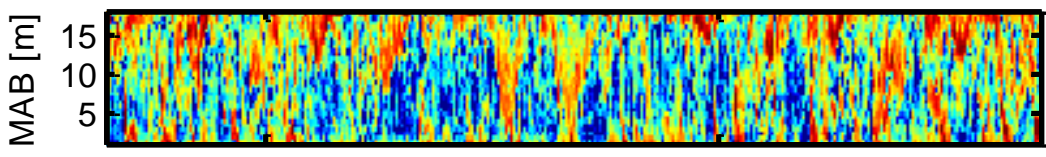

(b)
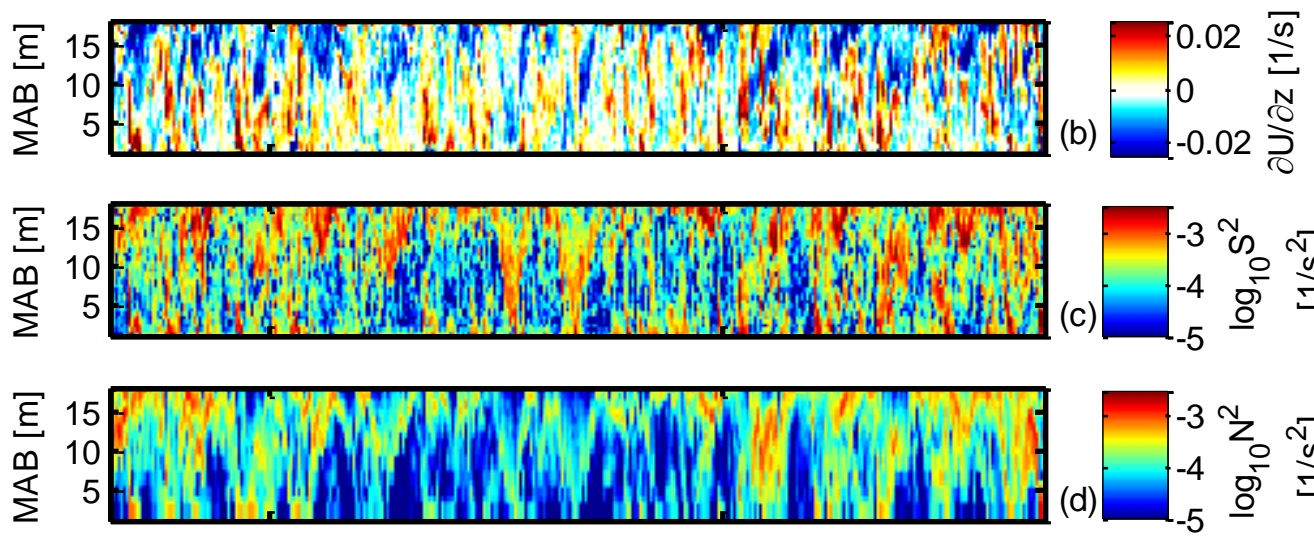

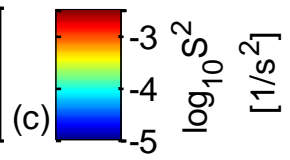
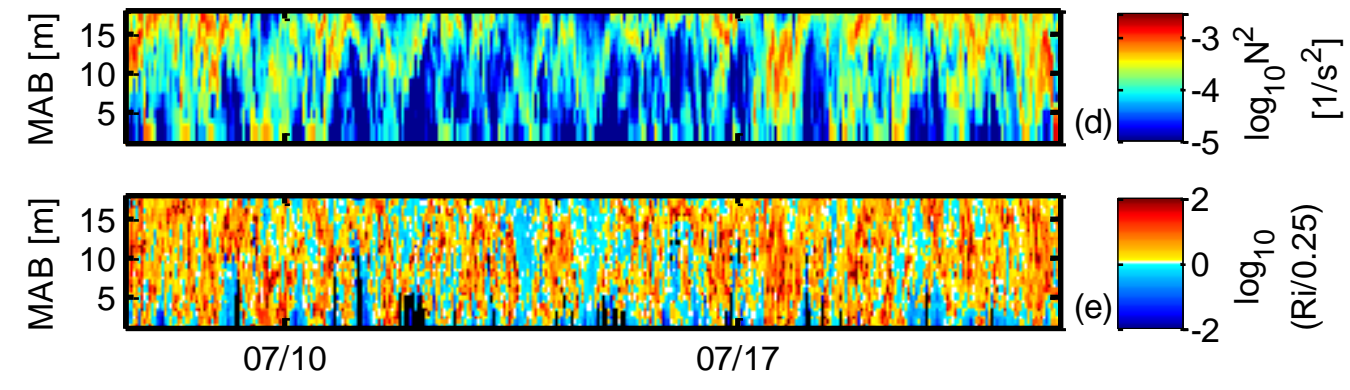

Figure 4: Time series during the entire study period highlighting the vertical structure of velocity shears and water column stability. Ten-minute averages of the (a) vertical shear of the alongshore velocity component, (b) vertical shear of the cross-shore velocity component, (c) total vertical shear in the horizontal velocity $\left(S^{2}\right)$, (d) buoyancy frequency squared $\left(N^{2}\right)$, and (e) the normalized logarithmic gradient Richardson number $[\log (R i / 0.25)<0$ is equivalent to $R i<0.25]$. 


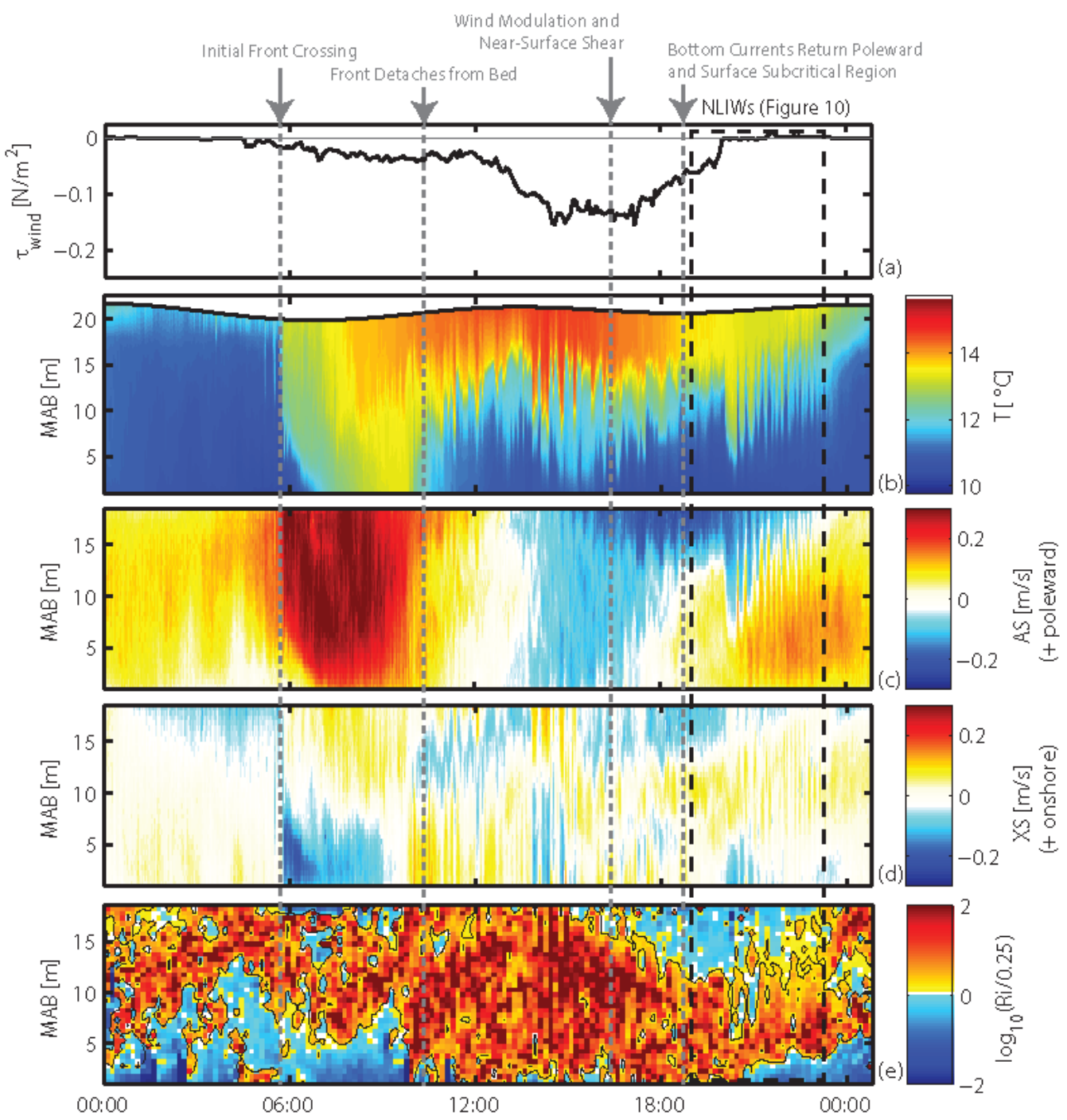

Figure 5: Detailed examination of the frontal crossing on 17 July 2011. (a) Time series of local along-shore wind stress (positive, poleward) from LML. (b) Temperature, (c) along-shore velocity (positive, poleward), and (d) cross-shore velocity (positive, onshore) contour plots from FDN. (e) Space-time variability of water column stability using the normalized, logarithmic gradient Richardson number $[\log (R i / 0.25)<0$ is equivalent to $R i<0.25]$. Ten-minute averages were used for the buoyancy frequency and vertical shear in the calculation of the gradient Richardson number. The black contour denotes regions where $R i=0.25$. The free surface height (black) is also shown in panel (b). The dashed black boxes denote the time period in Figures 11 and 14. 
Figure 6: Detailed examination of the frontal crossing on 8 July 2011. (a) Time series of local along-shore wind stress (positive, poleward) from LML. (b) Temperature, (c) along-shore velocity (positive, poleward), and (d) cross-shore velocity (positive, onshore) contour plots from FDN. (e) Space-time variability of water column stability using the normalized, logarithmic gradient Richardson number $[\log (R i / 0.25)<0$ is equivalent to $R i<0.25]$. Ten-minute averages were used for the buoyancy frequency and vertical shear in the calculation of the gradient Richardson number. The black contour denotes regions where $R i=0.25$. The free surface height (black) is also shown in panel (b). 
Figure 7: Schematic cartoon of the front and NLIW dynamics in the along-shore direction. (a) The buoyant plume front propagates along-shore poleward (+AS) past the mooring array. (b) The local diurnal winds arrest the poleward advection of the front so that it reverses and propagates downwind (along-shore equatorward). (c) The wind modulation results in the development of a strong near-surface shear layer, and as the local winds relax, the bottom portion of the water column returns to flow poleward. Large-amplitude NLIWs are observed in the presence of this strong background shear. Note that this schematic does not capture the full cross-shore structure. 
Figure 8: (a) Depth-averaged buoyancy frequency squared and (b) depth-averaged, high-pass filtered density $\left(\left\langle\rho^{\prime}\right\rangle\right)$ over the entire record. (c) Wavelet power spectrum of the density perturbations $\left(\left\langle\rho^{\prime}\right\rangle\right)$. Thick black lines on both ends of the spectrum indicate the "cone of influence" where edge effects become important. The thin black contour lines represent the $95 \%$ confidence level. (d) Scale-averaged wavelet power between 0.1 and $0.5 \mathrm{hrs}$ isolating the highfrequency internal wave band.

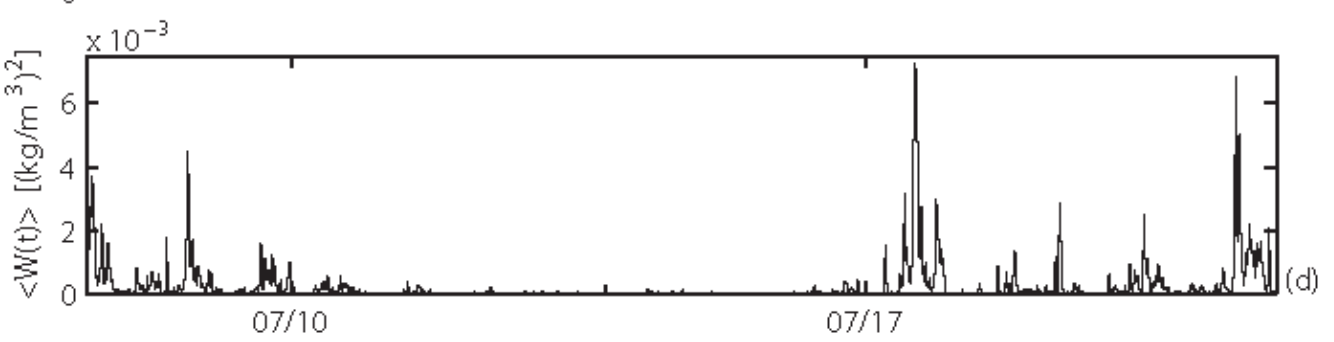


Figure 9: (a) Wavelet power spectrum of the near-bottom (1.3 mab) high-pass filtered kinetic energy $\left(K E^{\prime}\right)$ over the entire record. Thick black lines on both ends of the spectrum indicate the "cone of influence" where edge effects become important. The thin black contour lines represent the $95 \%$ confidence level. (c) Scale-averaged wavelet power between 0.1 and $0.5 \mathrm{hrs}$ isolating the high-frequency internal wave band. 

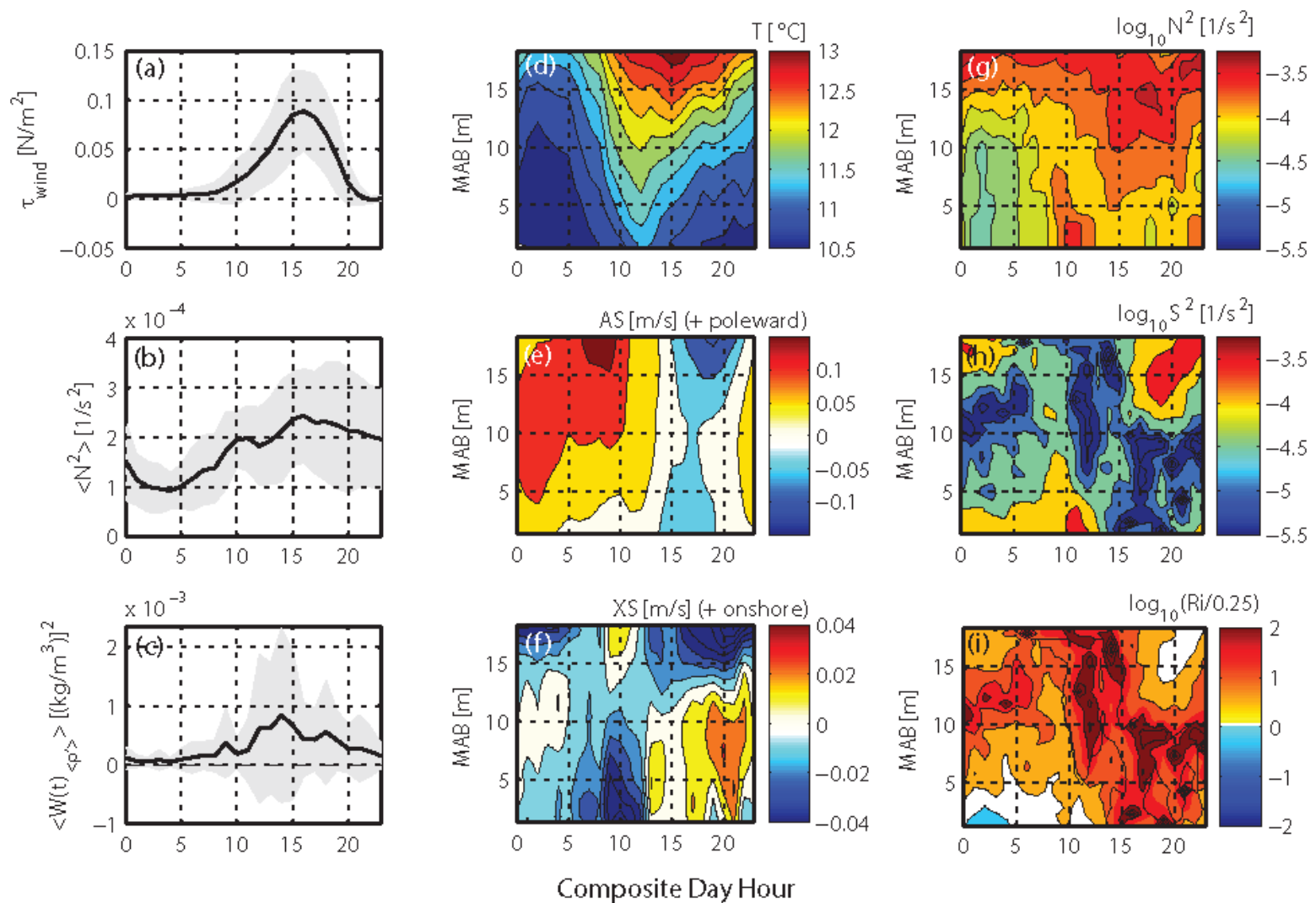

Figure 10: Composite day plots of (a) the local wind stress (5 min), (b) the depth-averaged buoyancy frequency squared (10 $\mathrm{min})$, and (c) the scale-averaged wavelet power of density perturbations $\left(\left\langle\rho^{\prime}\right\rangle\right)$ between 0.1 and $0.5 \mathrm{hrs}$ isolating the high-frequency internal wave band (as in Figure 8d, $1 \mathrm{~min})$. The gray shading represents one standard deviation from the mean. Composite day contour plots (10 min) of (d) temperature, (e) along-shore velocity (positive, poleward), (f) cross-shore velocity (positive, onshore), (g) buoyancy frequency squared $\left(N^{2}\right),(\mathrm{h})$ total vertical shear in the horizontal velocity $\left(S^{2}\right)$, and (i) normalized logarithmic gradient Richardson number $[\log (R i / 0.25)<0$ is equivalent to $R i<0.25]$. Composite day plots were created by computing the average value of each respective quantity (a-i), centered on each hour of the day (local time, PDT). The regional upwelling dominated period (13 to 15 July) was excluded to isolate frontal event variability. The averaging interval of the time series used for composite averaging is given in parentheses for each respective quantity (a-i). 
Figure 11: NLIW packet on 17 July 2011. (a) Density contour plot highlighting the NLIW packet. The pycnocline region is highlighted by the $1025.48 \mathrm{~kg} / \mathrm{m}^{3}$ and $1025.68 \mathrm{~kg} / \mathrm{m}^{3}$ isopycnals (thick black lines). Isopycnals are shown in $0.05 \mathrm{~kg} / \mathrm{m}^{3}$ increments from 1025.45 to 1025.85 $\mathrm{kg} / \mathrm{m}^{3}$ (thin black lines). One-minute averages showing the (b) along-shore (positive, poleward), (c) cross-shore (positive, onshore), and (d) vertical velocity fields. 

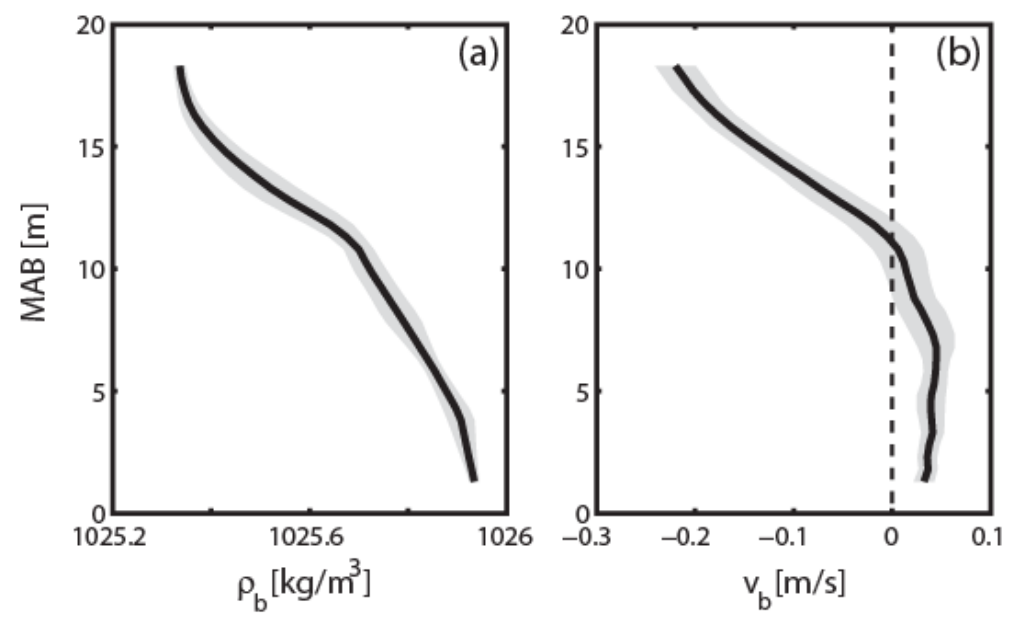

Figure 12: Vertical profiles of the mean (solid black) (a) density $\left(\rho_{b}\right)$ and (b) horizontal (i.e., along-shore, where positive is poleward) velocity $\left(v_{b}\right)$ for the period prior to the arrival of the NLIW train (18:25 - 19:15) on 17 July 2011. The standard deviation (grey shading) of the profiles over the same period is also shown, highlighting the quasi-steady state of the background flow. 

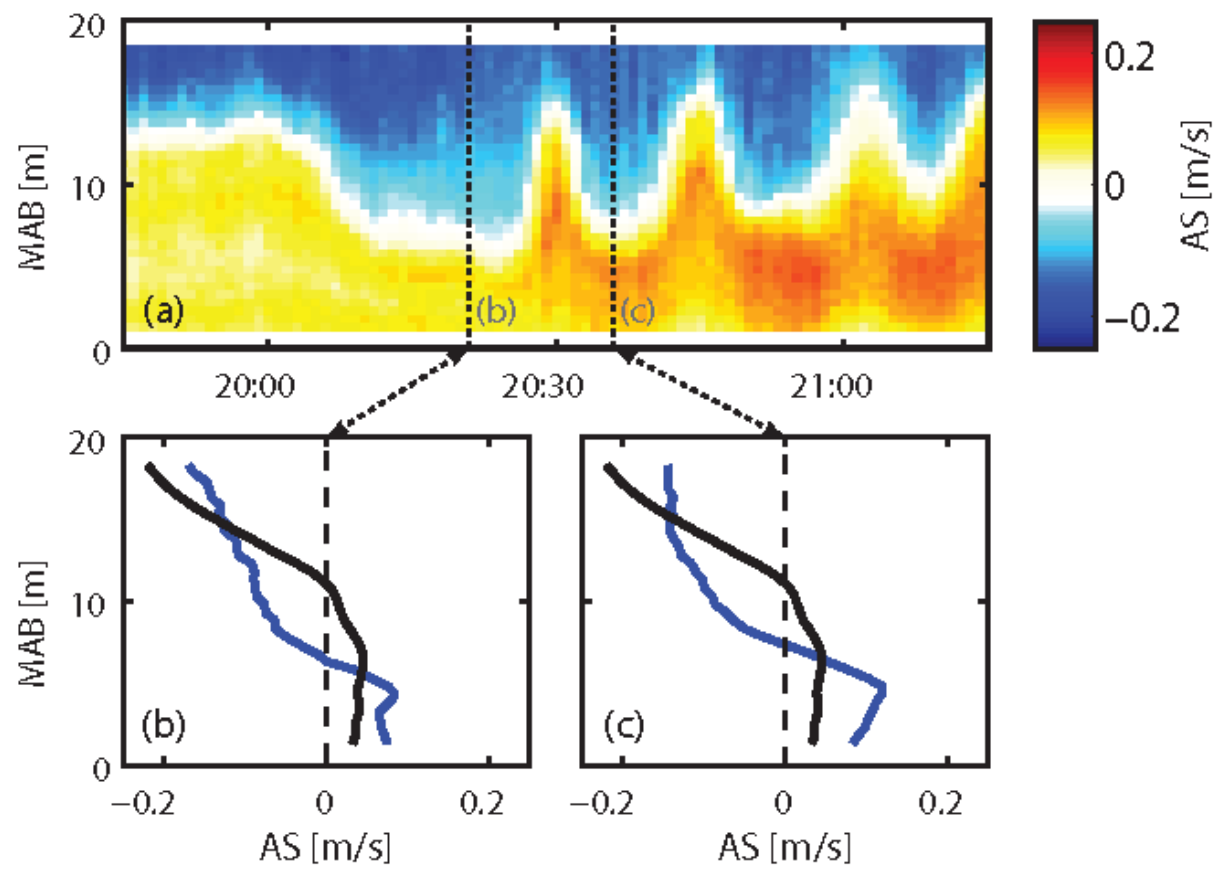

Figure 13: (a) Along-shore velocity (positive, poleward) contour plot of the leading waves in the NLIW train on 17 July 2011. The vertical lines (dotted, black) in panel (a) denote the times when the vertical velocity profiles plotted in panels (b) and (c) were taken (i.e., at the wave trough). The profiles correspond to the background along-shore velocity ( $v_{b}$, black) and total along-shore velocity at the wave trough ( $v$, blue) 
Figure 14: Space-time variability of the water column stability for the NLIW packet on 17 July 2011. The pycnocline region is highlighted by the $1025.48 \mathrm{~kg} / \mathrm{m}^{3}$ and $1025.68 \mathrm{~kg} / \mathrm{m}^{3}$ isopycnals (black lines), as in Figure 10. One-minute averages of the (a) total vertical shear in the horizontal velocity $\left(S^{2}\right)$, (b) buoyancy frequency squared $\left(N^{2}\right)$, and (c) the normalized logarithmic gradient Richardson number $[\log (R i / 0.25)<0$ is equivalent to $R i<0.25]$. 
(i) - No background current

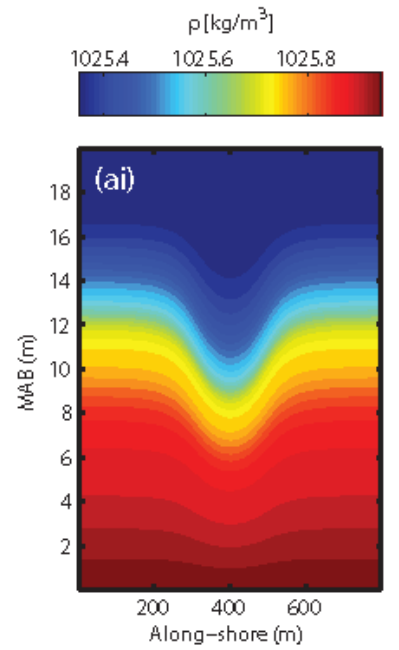

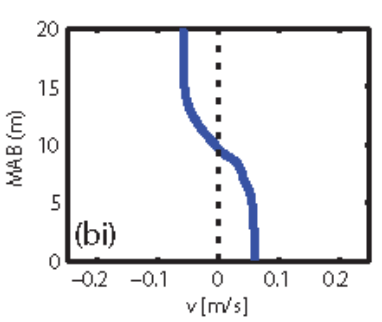

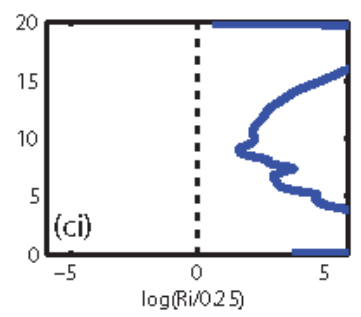

(ii) - Sheared background current

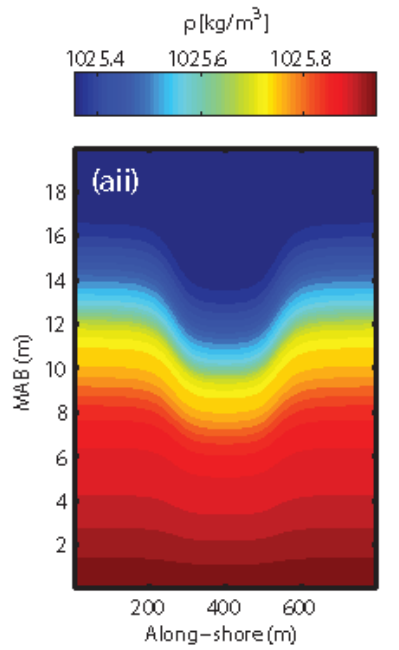

Figure 15: Solution to the DJL equation using the background density with (i) no background current and (ii) largest background current strength with which it was possible to compute waves (see text). Panel (a) shows a density contour plot, while panel (b) highlights vertical profiles of the background along-shore velocity $\left(v_{b}\right.$, black) and total along-shore velocity at the wave trough ( $v$, blue). (c) Vertical profile of the normalized, logarithmic gradient Richardson number $[\log (R i / 0.25)<0$ is equivalent to $R i<0.25]$ at the wave trough (blue). The dashed black line in panel (c) indicates $R i=0.25$. 

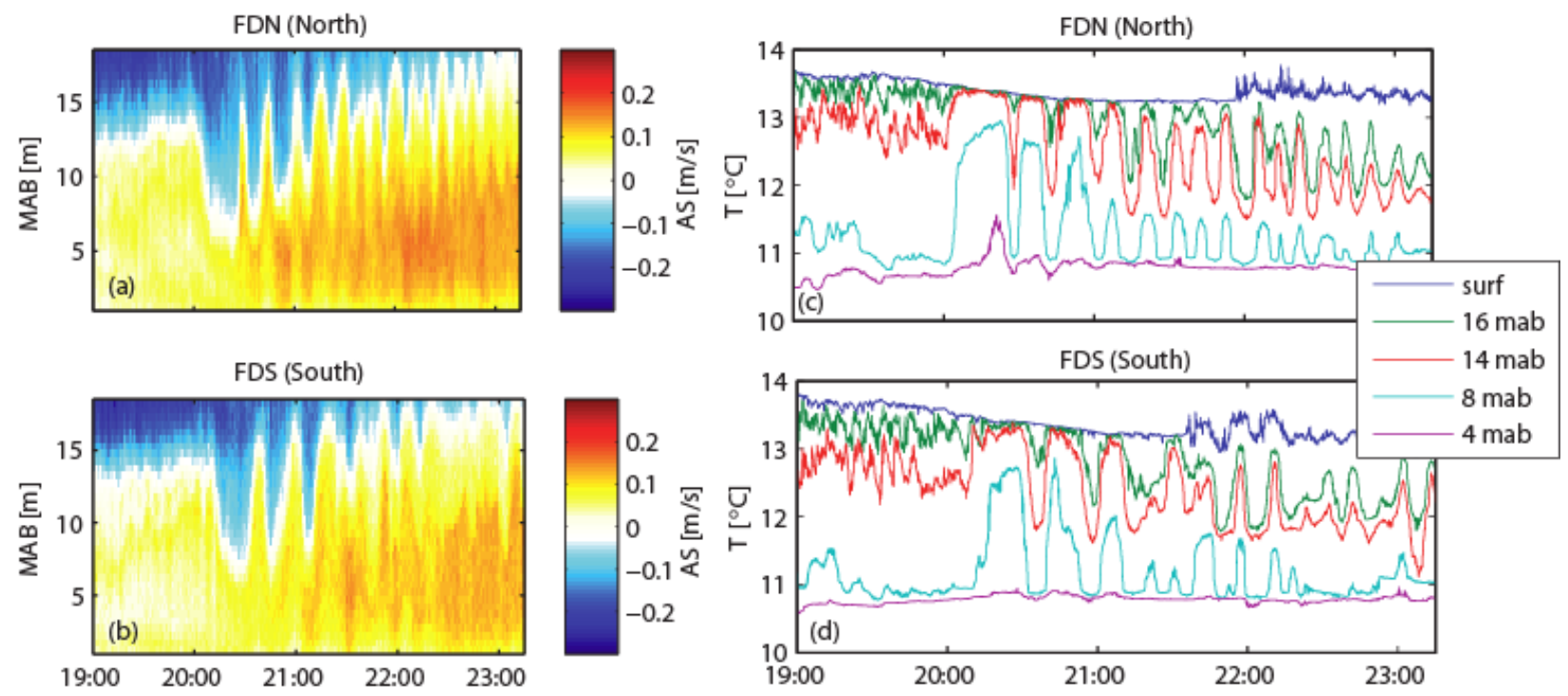

Figure 16: Evolution of the NLIW packet on 17 July 2011 between moorings FDN (north, top row) and FDS (south, bottom row). (a, b) One-minute averages of the along-shore (positive, poleward) velocity field. (c, d) Temperature time series for thermistors located at equivalent heights above the bed at the two locations (4, 8, 14, 16 mab, and surface). 